NBER WORKING PAPER SERIES

\title{
SOCIAL PROXIMITY AND BUREAUCRAT PERFORMANCE: EVIDENCE FROM INDIA
}

\author{
Guo Xu \\ Marianne Bertrand \\ Robin Burgess \\ Working Paper 25389 \\ http://www.nber.org/papers/w25389 \\ NATIONAL BUREAU OF ECONOMIC RESEARCH \\ 1050 Massachusetts Avenue \\ Cambridge, MA 02138 \\ December 2018
}

This paper has benefited from comments of seminar participants in Northwestern Kellogg, Uppsala, Columbia GSB, Barcelona Graduate School of Economics Summer Forum, UC Berkeley, UCDavis (Pacdev), Chicago Harris, the BPP-GEM workshop, the Stanford Quality of Governance workshop and the ABCDE World Bank conference. We thank Oriana Bandiera, Tim Besley, Michael Callen, Ernesto Dal Bo, Fred Finan, Olle Folke, Guido Friebel, Saad Gulzar, Julien Labonne, David Levine, Jan Pierskalla, Andrea Prat, Johanne Rickne, Daniel Rogger, Raul Sanchez de la Sierra and Noam Yuchtman for their valuable comments. Fraser Clark, Anton Heil, Rebecca Rose, Jinling Yang and Jiemin Xu provided excellent research assistance. The views expressed herein are those of the authors and do not necessarily reflect the views of the National Bureau of Economic Research.

NBER working papers are circulated for discussion and comment purposes. They have not been peer-reviewed or been subject to the review by the NBER Board of Directors that accompanies official NBER publications.

(C) 2018 by Guo Xu, Marianne Bertrand, and Robin Burgess. All rights reserved. Short sections of text, not to exceed two paragraphs, may be quoted without explicit permission provided that full credit, including $\odot$ notice, is given to the source. 
Social Proximity and Bureaucrat Performance: Evidence from India

Guo Xu, Marianne Bertrand, and Robin Burgess

NBER Working Paper No. 25389

December 2018

JEL No. J45,O43

\section{$\underline{\text { ABSTRACT }}$}

Using exogenous variation in social proximity generated by an allocation rule, we find that bureaucrats assigned to their home states are perceived to be more corrupt and less able to withstand illegitimate political pressure. Despite this, we observe that home officers are more likely to be promoted in the later stages of their careers. To understand this dissonance between performance and promotion we show that incoming Chief Ministers preferentially promote home officers that come from the same home district. Taken together, our results suggest that social proximity hampers bureaucrat performance by facilitating political capture and corruption.

Guo Xu

Haas School of Business

UC Berkeley

guoxu@haas.berkeley.edu

Marianne Bertrand

Booth School of Business

University of Chicago

5807 South Woodlawn Avenue

Chicago, IL 60637

and NBER

marianne.bertrand@chicagobooth.edu
Robin Burgess

Department of Economics, 32L.3.03

London School of Economics

Houghton Street London WC2A 2AE

United Kingdom

r.burgess@1se.ac.uk 


\section{Introduction}

The rise of nation states necessitated the formation of centralized bureaucracies to implement policies, coordinate economic activities and drive the development process (Evans 1995, Amsden 1989, Evans and Rauch 2000, Wade 1990). This required bureaucrats to put the national interest above private and local interests and much emphasis was placed on inculcating this mission of nation building (Weber 1978). Professional bureaucrats were expected to serve the state, not particular individuals, to separate their private business from the business of the state, to abide by clearly defined sets of rules and codes, and to spend their entire careers in the service of the nation. Across history, there has been a shift from local rulers executing key functions through kin, personal trustees and court-servants to permanent, professional bureaucracies running nation states. A central objective of such bureaucracies was to devise systems and rules that reduced the patronage and corruption that had plagued earlier systems of government (Northcote and Trevelyan 1854, Xu 2018).

Bureaucrats, however, originate from particular localities which they will have a particular knowledge of and affinity with. One question that all centralized bureaucracies face therefore concerns whether bureaucrats should be allowed to serve in the areas they originate from. This is the question we take up in this paper. We study whether and how social proximity between bureaucrats and where they work affects their performance. Given that bureaucrats constitute a key element of state capacity (Besley and Persson 2009, Finan et al. 2015), how they are allocated within a nation could have ramifications for the patterns of growth and development (Evans and Rauch 2000, Dal Bo et al. 2013).

The central tension in this context lies between delegation and control. The administration of any large organization requires striking a balance between the lack of local knowledge and the ability to control subordinates (Aghion and Tirole 1997, Alesina and Tabellini 2007, Alesina and Reich 2015, Dessein 2002, Moe 2012). On the one hand, assigning bureaucrats to socially proximate environments might enable them to leverage their informational advantage to improve performance. On the other hand, this same advantage might be exploited for private gain or to put local interests above the national interest.

This tension between exploiting local knowledge and avoiding local capture has been present throughout history. Roman rulers, for example, appointed local councils but frequently assigned an outside governor to oversee functions like tax collection (Woolf 2012). The royal officers who forged France into an early nation state were barred from holding office in their place of birth using the argument that "a paid official sent out by the government, who had no power network in the area to which he had been assigned, and, in the way of a true bureaucrat, owed his income and social status wholly to the central administration that he represented" was "fanatically loyal to the king" (Cantor 1993, p. 411-412). In Imperial China a similar "rule of avoidance" prevented district magistrates to serve in their home districts (Ebrey and Smith, 2016). Similarly, the British Colonial Office considered candidates for senior civil service positions with "local connexion with the colony by birth, family ties, or otherwise" as ineligible. ${ }^{1}$ These rules foreshadowed similar restrictions in

\footnotetext{
${ }^{1}$ Colonial Rules \& Regulations 1881, Chapter IV, $§ 1,75$.
} 
modern bureaucracies. However, running against this centralizing tide has been a recent shift back towards localization of public service delivery (World Bank 2004, Bardhan and Mookherjee 2006, Mansuri and Rao 2013, Mookherjee 2015, Casey 2018, Bandiera et al. 2018). This literature argues that agents recruited from the communities they serve are higher performing due to the informational advantages they possess. It therefore remains an open question whether allocating bureaucrats back to the localities from which they originate will enhance or hamper their performance.

To look at this issue we exploit variation in social proximity using plausibly exogenous variation in the assignment of Indian Administrative Service (IAS) officers to their home states in India. Social proximity, as captured by geographical distance and shared language, captures key aspects of local information (Fisman et al. 2018, Huang et al. 2017). Assigning bureaucrats to an area with shared language, culture or values, for example, may increase performance by allowing them to harness private information and social incentives (Besley and Ghatak 2018). Social proximity however may also decrease performance as bureaucrats abuse local networks, engage in corrupt behavior or are captured by local politicians and vested interests (Ashraf and Bandiera 2017).

Studying this issue for the IAS is particularly important as the close to 4,000 centrally recruited officers from this service effectively run India, heading up all government departments at both the central and state levels. At the beginning of their careers, IAS officers are allocated for life to an Indian state. Given their importance, the manner in which they are allocated across the country and whether or not officers are able to return to their home state could impact the implementation of state-level policies and country-wide patterns of growth and development (Asher and Novosad 2015, Bertrand et al. 2018).

Our empirical strategy leverages detailed institutional knowledge of the home state assignment rule to isolate a source of variation that (i) predicts the allocation to home state and (ii) is uncorrelated with observable individual background characteristics of the officers. In balancing the aims of equalizing the quality of administrators across the states of India whilst affording officers the chance of serving in their home state, the IAS uses a rule-based mechanism to deploy newly recruited officers to states. While higher ranked officers are more likely to be assigned to their home state, we exploit the fact that officers are grouped according to their caste $\times$ home state bracket when being ranked in the allocation process. This implies that officers who are the only candidate in their bracket in a given year of intake are allocated to their home state with near certainty. Variation in the bracket size, however, depends on whether officers from the same caste and state passed the competitive entry exam in the same year. We argue and provide evidence that officers are, conditional on the selection bracket, as good as randomly assigned to their home state.

The main finding is that home state allocated officers perform worse than comparable officers who are allocated to non-home states. Instrumental variable estimates suggest that officers allocated to their home states are deemed to be more corrupt and less able to withstand illegitimate political pressure. This effect is primarily driven by the home states that score higher on measures of corruption. Consistent with this subjective evidence we 
find that, in the more corrupt Indian states, home-allocated officers are more likely to be suspended primarily due to having court cases pending against them. We show that the performance gap between home- and non-home state IAS officers is particularly pronounced in the later career stages where, we argue, there is more room for patronage and capture of the bureaucracy by the local political elite.

We provide corroborating evidence that home officers, especially more senior ones, are more susceptible to political capture by the political elite by investigating differential patterns of political interference in the careers of IAS officers based on their proximity to Chief Ministers, the political heads of Indian states. In a high frequency monthly-level event study, we find that senior home officers are on average reshuffled more frequently, and more likely to be promoted in the immediate months following the appointment of a new Chief Minister. Furthermore, this surge in transfers and promotions is magnified for those home officers who originate from the same home district in the state as the incoming Chief Minister. The combined results are consistent with social proximity adversely impacting bureaucrat performance through political favoritism.

These findings are important as the question of how to allocate talent is central in organizations. Focusing on the one-off and life-long deployment of officers to states allows us to isolate bureaucrat-workplace match effects, thus providing novel evidence in a setting that hitherto primarily focused on the incentivizing role of frequent transfers (Iyer and Mani 2012, Khan et al. 2015, Jia 2015, Xu 2018, Khan et al. 2018), or its disruptive impact on service delivery (Akthari et al. 2018). By focusing on how to allocate already selected talent, we complement the literature on the negative selection effects of discretionary public sector hiring (Brollo et al. 2017, Colonelli et al. 2018, Weaver 2018). Finally, our results also resonate well with the historical literature which highlights the tension between the need for local knowledge and the challenge of capture and clientelism in settings ranging from the administration of Empire to the allocation of modern day civil servants and ambassadors (Kirk-Greene 2000, Newbury 2003, Greif 2007).

The rest of the paper is organized as follows. In Section 2, we present data sources and institutional background, focusing on the allocation rule we exploit as a source of exogenous variation. Section 3 describes our empirical strategy. Section 4 reports the main findings on the relationship between bureaucrat performance and home allocation, as well as heterogeneity in this relationship across Indian states and career stages. Section 5 provides evidence on the differential patterns of political interference in the transfers and promotions of home vs. non-home state IAS officers. We conclude in Section 6.

\section{Background and data}

The Indian Administrative Service (IAS), the successor of the Indian Civil Service (ICS), is the elite administrative civil service of the Government of India. ${ }^{2}$ In 2014 the IAS had an overall strength of around 3,600 centrally recruited officers. These officers are civil service

\footnotetext{
${ }^{2}$ See Iyer and Mani (2012) and Bertrand et al. (2018).
} 
leaders, occupying key positions critical for policy implementation. The most senior civil service positions - the Cabinet Secretary of India, the Chief Secretary of States, heads of all state and federal government departments - are occupied by IAS officers.

The recruitment of officers is based on the performance in the Civil Service Exam, which is annually organized by the Union Public Service Commission (UPSC). Entry into the IAS is extremely competitive, with several hundred thousand applicants competing for a small number of spots. In 2015, for example, 465,882 UPSC exam takers faced only 120 IAS slots. Those who do not qualify for the IAS may obtain positions in less competitive civil service streams such as the Indian Police Service (IPS), the Indian Forest Service (IFS), the Indian Revenue Service (IRS) or the state civil services. The highest performing exam takers are typically offered slots in the IAS. There are quotas for the reserved castes, namely the Other Backward Castes (OBC), Scheduled Castes (SC) and Scheduled Tribes (ST). Once selected, IAS officers are allocated to a state cadre. The assignment to a state is fixed for life $^{3}$ and officers are attached to their state cadre even when serving in Delhi or abroad. After selection and allocation to a state cadre, IAS officers undergo training at the Lal Bahadur Shastri National Academy of Administration (LBSNAA) and in the states. The two-year training consists of one year academic training at the LBSNAA ("course work") and one year practical training ("district training"). After training, recruits are initially placed in the district administration (e.g. as district collectors), and are subsequently promoted to higher level positions. Finally, retirement occurs at 60 years of age for both male and female officers (58 years before 1998).

\subsection{Data}

We leverage several datasets for our study. The main dataset on performance indicators and background characteristics builds on a data collection effort linking administrative records to a large-scale performance survey we conducted (Bertrand et al. 2018). We add to this core dataset newly collected data on the spells and background characteristics of Chief Ministers between 1980-2012. In the following section, we describe the key data used in our analysis. Detailed information about the data collection and the methodology of the performance survey can be found in the Appendix C.1.

Subjective performance ratings. Bertrand et al. (2018) introduce a new framework to measure the performance of civil servants based on subjective performance ratings. Performance scores were collected for a cross-section of centrally recruited IAS officers working in the 14 major states of India ${ }^{4}$ with at least 8 years of tenure. These scores were provided by a wide range of stakeholders in each state, ranging from IAS officers, state civil servants, and politicians (MLA) to representatives of media, business and NGOs. Each officer was scored on a scale of 1 (low) to 5 (high), covering five dimensions of performance: effectiveness, probity, the ability to withstand illegitimate political pressure, pro-poor orientedness

\footnotetext{
${ }^{3}$ The only exception for transfers across states is in the case of marriage to another IAS officer. These cases, however, have to be approved on a case-by-case basis and are rare.

${ }^{4}$ These are: Andhra Pradesh, Bihar, Gujarat, Haryana, Karnataka, Kerala, Madhya Pradesh, Maharashtra, Orissa, Punjab, Rajasthan, Tamil Nadu, Uttar Pradesh and West Bengal.
} 
and overall performance. Overall, the survey covered 1,472 bureaucrats who were serving in 2012-13 and with at least 8 years of tenure. This corresponds to a coverage rate of $71 \%$.

Administrative data. We link the survey data on performance with administrative data from the descriptive rolls, the inter-se-seniority lists and the executive sheets. The descriptive rolls contain a rich set of individual background characteristics for 5,635 officers who entered between 1975-2005. Characteristics range from year of birth, their home state, caste, family background, educational degrees and work experience. The dataset also contains information about the permanent address of the officers at time of application, allowing us to identify the home districts of the IAS officers.

The inter-se-seniority lists cover 4,107 officers from 1972-2009. This dataset provides information about the allocation of officers to states as well as their scores on the entry exam, training course and overall rank. Finally, the executive record sheets cover the postings of 10,817 IAS officers who entered between 1949-2014. These records contain detailed information about postings and payscales, allowing us to track the progression of IAS officers over time. After linking all administrative sources, the dataset covers up to 1,888 IAS officers who entered between 1976-2005.

Chief Minister data. We obtain information on the Chief Minister terms for all states in the period between 1980-2010. For each of the 132 Chief Ministers, we collect information about their birth location, district and, if available, caste. To collect this information, we consulted printed biographies and searched through newspaper articles. Given the seniority of these politicians, the information is readily available.

Table 1 reports the mean and standard deviation of the performance scores. The sample sizes range from $N=15,153$ for the probity measure to $N=17,753$ for the effectiveness measure. The number of complete assessments across all dimensions is $N=14,037$. We were able to elicit scores for about $71 \%$ of all IAS officers in our sample. All dimensions are correlated, with the highest correlation being between pro-poor orientation and the ability to withstand illegitimate political pressure.

Table 2 compares the average individual characteristics of officers who are allocated to their home state vs. those who are not. The sample comprises all IAS officers who entered between 1975-2005. The table compares both the raw average (Column 3) and the average difference within each year of intake (Column 4). In accordance with the merit-based home state allocation (see next section for a detailed description), home state-allocated officers tend to rank, on average, higher. Within a given intake, officers who receive their home state rank on average 15 positions higher than those who do not. The non-random allocation for home state-officers also translates into significant differences on other margins: home state-allocated officers are, on average, less likely to be from the Other Backward Castes and more likely from Scheduled Castes. More generally, a joint hypothesis test rejects the null that home state-allocated officers are, on average, comparable to non-home state officers. 


\subsection{Allocation rule}

We describe the rule governing the allocation of IAS officers to state cadres in detail as this will generate the critical source of variation for our analysis. ${ }^{5}$ We focus on the allocation rule that has been in place throughout the cohorts 1984-2005. ${ }^{6}$ The allocation follows a strict rule-based procedure. After entering the IAS following the nation-wide entry exams administered by the Union Public Service Commission (UPSC), the centrally recruited officers are allocated to 24 cadres. These cadres typically map directly into the Indian states. $^{7}$ The allocation process can be divided into three steps. In the first step, IAS applicants are asked to declare their preference to remain in their home state (referred to as insider preference). In the second step, the overall number of vacancies and the corresponding quotas for castes and insiders are determined. In the final step, vacancies and officers are matched in the actual allocation process.

Step 1. IAS officers declare their preference to remain in their state of residence. Since the allocation to a cadre is life-long and the home preference the only margin of cadre choice, nearly all IAS officers exercise the option to remain in their home state. ${ }^{8}$ For the 2006 intake, for example, 87 out of the 89 recruited officers declared a home state preference. The declared preference however does not guarantee the actual allocation as the assignment depends on the availability of vacancies.

Step 2. The total number of vacancies is determined by the state government in conjunction with the Department of Personnel and Training (DoPT). Typically, the overall number of vacancies in a given year depend on the shortfall from the total number of IAS officers designated to a state - the cadre strength. ${ }^{9}$ This cadre strength is defined by the "cadre strength fixation rules", which reserves more IAS officers for the larger states. These rules are seldom revised so the designated state cadre strength is fixed over longer periods. The vacancies are then broken down by quotas on two dimensions: caste and home preference. There are three categories for castes: General (unreserved) caste, Scheduled Caste/Tribes (SC/ST) and Other Backward Castes (OBC). The designation of vacancies to these caste categories are made based on predefined national quotas. The actual assignment of each vacancy to a caste is randomized using a rotating roster. In terms of preferences, vacancies are broken down into "insider" and "outsider" vacancies. Insider vacancies are to be filled by IAS officers from the same state who declared their home state preference at

\footnotetext{
${ }^{5}$ The exact documentation can be found in the IAS guidelines. Refer to the original official notifications: 13013/2/2010-AIS-I, 29062/1/2011-AIS-I and 13011/22/2005-AIS-I published in the Department of Personnel and Training, Ministry of Personnel, Public Grievances and Pensions, Government of India. Note that we describe the dominant allocation rule in our study period 1976-2005. The rule was reformed in 2008.

${ }^{6}$ Between 1978-1984, officers were allowed to also declare preferred "zones" (i.e. groups of states) for the outsider allocation (the "Limited Zonal Preference System"). After 2008 (and thus beyond our study period), officers were allowed to declare their preferences beyond a home state allocation by ranking the states in their preferred order (the "Merit-cum-preference system").

${ }^{7}$ Smaller states, however, are grouped into three joint cadres, which are Assam-Meghalaya, ManipurTripura and AGMUT (Arunachal Pradesh, Goa, Mizoram and Union Territories (Delhi). We did not survey states with pooled cadres due to logistical constraints.

${ }^{8}$ Not declaring home preference opens the possibility to be allocated to any other state (See Step 3).

${ }^{9}$ We find no evidence for selective sorting in response to variation in vacancies (Appendix Table B1). Given the competitiveness of the entry into the IAS, strategic concerns of exam participation are negligible.
} 
time of application. The ratio of insider to outsider vacancies is $1: 2$, with the assignment of vacancies to "insider" or "outsider" category following the repeating sequence O-I-O. The determination of vacancies is shown in Appendix Figure A1. The result of this procedure is a list denoting the number of vacancies for each state and the corresponding quotas by caste (GEN/SC/ST/OBC) and home state (Appendix Figure A2).

Step 3. The final allocation process is based on merit as determined by the ranking in the UPSC entry exam, the vacancies available and the home preference declared. Before the officers are allocated, the candidates are ranked and assigned a serial number in the order of merit, as determined by the UPSC entry exam. Appendix Figure A3 shows this ranking along with the officers' caste and home preference. The highest scoring candidate for the 2006 intake, for example, belongs to the OBC category and indicated a preference to be assigned to the home state of Andhra Pradesh.

Home state assignment. The insider vacancies are allocated as far as exact matches along caste and home state preference (the allocation "bracket") permit. If the number of matches exceed the vacancies, the higher ranking IAS officer is given preference. Since the exact match along caste and home state is required for slotting, however, many insider vacancies typically remain unfilled. In this case, the caste requirement is successively relaxed, eventually opening to outsiders. ${ }^{10}$

Non-home state assignment. The allocation of the "outsiders" and those who failed to be allocated to their preferred home state (and are consequently converted to outsiders) is done according to a rotating roster system. In a nutshell, the rotating roster is designed to ensure that each state receives, on average, candidates of similar quality across years. ${ }^{11}$

The critical feature for our empirical strategy is that home state officers are grouped and ranked within caste $\times$ home state brackets in each year of intake. The size of the bracket will vary across years depending on how many candidates from the same home state and caste pass the entry exam. This is the identifying source of variation we exploit. While the allocation rule for outsiders saw minor adjustments over time, this feature of the home state allocation has remained constant throughout the cohorts we study.

\section{$3 \quad$ Empirical strategy}

The key empirical challenge to estimating the causal effect of home state allocations is that the assignment of IAS candidates to home cadres is, unlike the overall assignment rule, non-random. Indeed, under the allocation rule outlined above, higher ranked IAS officers are given priority in their declared preference to be allocated to their home state. As higher ranked officers are prioritized for their home state allocation (Bhavnani and Lee 2018), a simple comparison between home state vs. non-home state officers is likely to yield upwardly biased estimates of the effect of home allocation on bureaucratic performance. We therefore need an instrument that predicts the likelihood of an officer receiving a home state allocation, but that is otherwise not correlated with the outcomes of interest.

\footnotetext{
${ }^{10}$ The details are not directly relevant to the identification strategy and thus discussed in Appendix B.2.

${ }^{11}$ The exact details are not directly relevant for our identification strategy and we refer to Appendix B.3.
} 
Our empirical strategy exploits knowledge of the rule-based home state allocation: we argue that home state allocation is, conditional on the allocation rule, as good as randomly assigned. Specifically, we predict home state allocation using the fact that the ranking of IAS officers for home state allocation occurs within pre-defined brackets. Instead of giving officers priority in their home state preference in descending order of their overall rank, officers are ranked within "brackets" based on their year of intake, home state and caste (e.g. 2015-Gujarat-OBC). Depending on corresponding vacancies, officers are then slotted in descending order of rank within their bracket.

One key implication of this rule is that there will be variation in the number of officers who are competing for home state allocations in the same bracket over time. To illustrate this, Figure 1 plots the number of home state allocations and the number of candidates for the Uttar Pradesh-Scheduled Caste/Tribe bracket for different years of intake. As the figure first shows, of course, home state allocations never occur in years when there is no Scheduled Caste/Tribe candidate from Uttar Pradesh. More importantly, it is apparent from the figure that whether or not an IAS officer gets assigned to his or her home state is (mechanically) negatively correlated to the total number of officers in the same bracket.

More generally, Figure 2 plots the probability of a home state allocation for a given officer as a function of the number of candidates in the same bracket relative to being a single candidate. Compared to a single candidate, having another candidate in the same bracket decreases the probability of a home state allocation by $16 \%$ points. The probability is $54 \%$ points lower when facing more than 8 other candidates. As the histogram shows, however, most of the variation in the number of candidates occurs between a single and two candidates. $42 \%$ of the allocation brackets comprise only a single candidate, and $21 \%$ contain two candidates. Only $9.6 \%$ of the brackets contain more than 8 candidates. $^{12}$

In light of this, we propose to predict home state allocation using a dummy that equals 1 if the officer is the only candidate in his or her year of intake-home state and caste bracket, 0 otherwise. This captures not only the most relevant margin of variation but is also the cleanest case: provided a vacancy is available, a single candidate IAS officer who indicated a home preference will surely be allocated to the home state. The main results, however, also hold up using the total number of candidates in the bracket as an instrument.

It is important to stress that whether or not a given officer is the single candidate in their bracket is exogenous: it depends solely on whether someone else from the same caste and the same home state in the very same year qualified for the IAS, which itself depends solely on the results of the Civil Service Exam. To formally test this, Table 3 compares individual characteristics of IAS officers who are single candidates vs. those who face multiple candidates for the intake years 1975-2005. While there remain average differences in the raw comparison, these differences vanish once we compare within the year of intake and within the same home state-caste bracket (Column 4). Once we control for the exact allocation rule, officers who are single candidate vs. multiple candidates are by and large on average comparable on observables. The only statistically significant difference is on

\footnotetext{
${ }^{12}$ These brackets are located in large states such as Uttar Pradesh. The overall share of only candidates does not vary significantly across state population, development or corruption levels (Appendix Table B2).
} 
gender. Our results, however, also hold when confining the sample to only male IAS officers (which comprise $86 \%$ of the officers in our sample). We cannot reject the joint equality of means along the rich set of individual characteristics.

More formally, we predict the home allocation for individual $i$ as follows:

$$
\text { home }_{i}=\beta \times \operatorname{only}_{K(i) T(i)}+\delta^{\prime} x_{i}+\nu_{K(i)}+\delta_{T(i)}+\varepsilon_{i}
$$

where home $_{i}=1$ if the officer $i$ is allocated to the home state. The dummy only $y_{K(i) T(i)}=1$ if the officer was the only candidate in the caste-home state cell $k=K(i)$ in the intake year $t=T(i) . \nu_{K(i)}$ are fixed effects for the allocation "bracket" (caste (GEN, OBC, SC/ST) $\times$ home state) and $\delta_{T(i)}$ are intake year fixed effects (1975-2005). $x_{i}$ are additional controls for individual characteristics: they include the UPSC entry exam rank FEs, gender, as well as educational and career backgrounds. These are a dummy that is 1 if the officer studied a STEM or Economics degree, a dummy if the officer received an academic distinction, and dummies for the previous types of jobs the officer held before entering the IAS (education/research, finance/banking, private/SOE, public, public AIS). $\varepsilon_{i}$, the error term, is clustered at the home state-caste-intake level - the level at which the instrument varies.

Table 4 reports the estimates for equation (1). Controlling for intake year fixed effects and caste-home state fixed effects, officers who are the single candidate in their home statecaste bracket are $22.8 \%$ points more likely to be allocated to the home state (Column 1 ). The coefficient remains stable when holding constant the overall rank of the candidate (Column 2) and controlling for a rich set of individual characteristics (Column 3). The first stage is strong: compared to the mean of the dependent variable (0.277), being an only candidate increases the probability of a home state allocation by $90 \%$. Finally, Column 4 conducts a placebo exercise by using variation in the officer's corresponding home state-caste bracket size in the two previous and future intake years. This exercise is also summarized in Figure 3, which plots the estimated coefficients for the impact of being an only candidate for two periods around an officer's year of intake. As the figure shows, it is only the contemporaneous bracket size that determines the propensity of a home state allocation. The estimates for the leads and lags are close to zero and statistically insignificant. Given the exogenous nature of the variation in being a single candidate, the inclusion of a rich set of individual-level controls leaves the point estimates nearly unchanged. Overall, the results in Tables 3, 4 and Figure 3 lend support to the validity of the instrument, providing evidence for both a first-stage and balance across a rich set of observable individual characteristics.

Having established the first-stage, Table 5 shows that home state assignments indeed increase social proximity. As expected, home state allocated officers are more likely to serve closer to their home district, as measured by the distance (in miles) between the allocated state's administrative capital and the officer's home district headquarter. ${ }^{13}$ The instrumental variable estimate, for example, suggests that the home district of officers

\footnotetext{
${ }^{13}$ In India, each district's administrative capital is referred to as the district headquarter. This is typically the city with the largest population after which the district is named. We use the vincenty distance when computing the distance between two locations.
} 
allocated to their home states lie, on average, 495 miles closer to the state's administrative capital (Column 1, Panel B). This is an important metric as officers serve a majority of their later career assignments in the state capital. Geographic proximity is also highly correlated with social proximity (Huang et al. 2017). Indeed, as shown in Table 5, Panel B, Column 2, officers allocated to their home states are also $83 \%$ points more likely to speak the allocated state's first language as their native language. Boasting 23 official languages, there is substantial variation in the first languages spoken across India. Linguistic proximity is thus an important measure of social proximity. Finally, Column 3 computes the distance between the home district of IAS officers and serving Chief Ministers in 2012. Since nearly all Chief Ministers originate from the state they serve, home state allocated officers are also significantly more likely to be closer to the Chief Ministers' home district. The results thus consistently confirm the role of home allocations in increasing social proximity.

\section{Home state allocation and performance}

\subsection{Main results}

We estimate the effect of home state allocation by comparing officers who enter the IAS as the single candidate in their home state $\times$ caste bracket to officers who enter with multiple peers from the same state and caste. We estimate for officer $i$ rated by respondent $j$,

$$
y_{i j}=\beta \times \widehat{\operatorname{hom}_{i}}\left(\operatorname{only}_{K(i) T(i)}\right)+\delta^{\prime} x_{i}+\theta_{j}+\nu_{K(i)}+\delta_{T(i)}+\varepsilon_{i j}
$$

where $y_{i j}$ is the performance score of the officer by survey respondent $j$ in 2012-13. We instrument home state allocation using a dummy that is 1 if the IAS officer is the only candidate in the home state-caste bracket in that intake year, and 0 otherwise. As before, $x_{i}$ is the rich set of individual-level controls as discussed in Section 3. $\theta_{j}$ is a respondent fixed effect, $\nu_{K(i)}$ is the fixed effect for the allocation "bracket" (caste $\times$ home state), $\delta_{T(i)}$ are intake year fixed effects and $\varepsilon_{i j}$ is the error term which we cluster at the intake yearhome state-caste level - the level at which the instrument varies - and the individual-level $i$ - as a single officer is rated by several respondents.

The key parameter of interest is $\beta$, which captures the performance difference between a home state vs. non-home state officer. Equation (2) makes precise where the identifying variation is coming from. Intuitively, we compare the perceived performance of officers who are single candidates in their allocation bracket to those who are not, conditional on the selection rule, as implemented using the $\nu_{K(i)}$ fixed effects. Holding the caste $\times$ home state bracket constant, the identifying assumption is that variation in being a single candidate (or not) in the allocation bracket at entry into IAS across different years of intake does not directly affect performance other than through the home state allocation rule.

Table 6 presents the performance results. Panel A reports the OLS estimates while Panel $\mathrm{B}$ reports the IV estimates. All columns use the same specification, except that we vary the dependent variable to span the five dimensions of bureaucrat performance collected in our subjective performance survey. While OLS estimates suggest that home state-allocated 
officers perform, if anything, better than non-home state officers, the IV estimates yield consistently negative effects. This pattern can be rationalized in light of our discussion of the home state allocation rule and the evidence in Table 2, which led us to expect that the OLS estimates would be upward-biased. In terms of point estimates, home state allocated officers are perceived to perform worse on all margins. Most importantly, home state-allocated officers are perceived to be statistically significantly less able to withstand illegitimate political pressure and more likely to be corrupt. The magnitudes are large. For the inability to withstand illegitimate political pressure, the effect represents an $11 \%$ decline when evaluated against the mean of the dependent variable. Finally, Figure 4 provides visual evidence for this effect. Mirroring the visual evidence in Figure 3, we find that leads and lags in being the only candidate does not affect the perceived ability to withstand illegitimate political pressure. ${ }^{14}$ The contemporaneous impact of being an only candidate, coinciding with the higher propensity of home state allocation in Figure 3 , however, is negative. As before, given the plausibly exogenous variation in entering as the only candidate in a selection bracket, the inclusion of a rich set of individual-level controls does not substantially affect the point estimates. These results suggest that social proximity, as measured by home allocation, negatively impacts bureaucratic performance.

These results are robust to changes in specification and subsamples. To ensure that the results are not only driven by the local variation in moving from single to multiple candidate brackets, we also confirm the robustness of the results when using the total number of candidates in a selection bracket to instrument for the likelihood of a home state allocation (Appendix Table B4). The results are also robust when dropping the pre-1984 intakes, where the allocation rule for "outsiders" differed slightly from the 1984-2008 rule. In addition, a potential concern with subjective measures is that these may not reflect objective performance. If respondents perceive home state officers to be more corrupt or have a higher "bar" in assessing their performance, the results may merely reflect bias and not actual performance differences. We assessed the possibility of bias by conducting the following robustness check: if the results reflect biased perceptions, we may expect the negative effects to be primarily driven by those who did not directly interact with the officer. The results in Appendix Table B5, however, suggest that the negative gap is driven by those who have directly interacted with the given IAS officer. When breaking down the result by stakeholder, we find that the negative gap is driven by reports from colleagues of home state officers. That said, we find notable differences across stakeholder groups: while IAS officers and their colleagues in the state civil service perceive home state officers to be unable to withstand illegitimate political pressure, politicians (MLA) themselves disagree, reporting a higher score on the ability to withstand pressure (Appendix Table B6). We find no evidence that the perceptions of home state officers are less noisy, as measured by the standard deviation of the subjective performance scores provided for a given officer across different respondents (Appendix Table B7). ${ }^{15}$

\footnotetext{
${ }^{14}$ Appendix Figure A5 shows the same results for all performance dimensions.

${ }^{15}$ The sample size declines as we require the same respondent to be rated by two different respondents in order to compute the standard deviation.
} 


\subsection{State-level heterogeneity and suspensions}

Our results so far suggest that officers allocated to their home states are deemed to be more corrupt and less able to withstand illegitimate political pressure than officers who are allocated to other states. As we discussed earlier, there are competing views about the possible effects of social proximity on bureaucratic performance. Greater social proximity means that bureaucrats have more information about the local context, and find it easier to communicate with the citizens they are serving. Better information and lower communication costs may thus improve bureaucratic performance. Moreover, local bureaucrats may simply care more about helping the communities they are representing due to the personal ties they have to these communities. On the other hand, local officers may be more susceptible to capture by the political elite. Their deeper personal networks in the community they serve may also provide more opportunities for bribe taking as well as a more efficient technology for bribe extraction. We therefore explore several sources of heterogeneity to shed light on the mechanisms underlying the effects.

If a home state allocation increases bureaucratic corruption and reduces the ability of bureaucrats to withstand illegitimate political pressure, we may expect these effects to be larger in states with weaker institutions, e.g. states where bureaucrats and politicians may have more discretion to bend the rules for their private benefits. To test this, Figure 5 breaks down the effect for the ability to withstand illegitimate political pressure by state to study the heterogeneity across India. ${ }^{16}$ We focus on reduced forms as the corresponding firststages are weaker due to the finer bins arising from having to estimate state-specific home state effects. We observe substantial heterogeneity across states: the negative home state effect is largest in Karnataka, Bihar, and Gujarat. Karnataka and Bihar are consistently ranked among the most corrupt regions of India. In contrast, this negative effect is close to zero or even reverted in Punjab, West Bengal and Andhra Pradesh. To understand whether the observed state-level heterogeneity is systematically related to measures of corruption and development, Table 7 allows the impact to vary by the average state-level corruption, as measured by the Transparency International Index used in Fisman et al. (2014), and the Human Development Index in 2007. Table 7 confirms the visual evidence. The negative effect on the ability to withstand illegitimate political pressure is driven by the states that score higher on the TI corruption index (Column 1). We also include the interaction with the human development index to assess whether the corruption measure is picking up cross-state differences in economic development. While we cannot rule out unobservable correlates, the role of corruption in magnifying the negative impact of home state allocations is strikingly persistent even after holding constant differences in development (Column 3). These results are consistent across all subjective performance measures (Appendix Table B8). For succinctness, we summarize this in Column 4 by presenting the results using an index derived from averaging across all performance dimensions.

Finally, we revisit the concern that subjective performance measures may not adequately capture actual performance. For example, respondents in corrupt states may be biased

\footnotetext{
${ }^{16}$ For completeness, Appendix Figure A6 shows the results for all dimensions of performance.
} 
towards expecting home officers to be more corrupt. To ensure that the results indeed reflect tangible performance differences, we turn our attention to direct evidence. In the remaining Columns 5-6 of Table 7, we leverage the executive record sheets to extend the cross-section into an individual-year panel 1980-2011. We focus on suspensions as the key measure of corrupt behavior and non-performance. As described in Bertrand et al. (2018), suspensions are rare and extreme outcomes, with the unconditional suspension rate only $0.8 \%$. Most suspensions involve corruption scandals, with court cases pending against the officers. As Appendix Table B3 also shows, both contemporaneous and past suspensions are negatively correlated with our subjective measures of performance. While home state officers are not differentially likely to be suspended on average (the TI corruption index is centered around the sample mean), their suspension probability increases significantly in states that score higher on the corruption index. An increase in the state-level corruption index by 1 SD increases the differential suspension rate for home state officers by $0.4 \%$ points (Column 5 ). Finally, Column 6 interacts the instrument with the state-level HDI. The results remain robust using suspensions as a direct measure of performance, thus alleviating concerns that the main results are driven by subjective biases.

\subsection{Individual-level heterogeneity and career dynamics}

We move from state-level heterogeneity to exploring individual-level heterogeneity. We are interested in how the career dynamics between home vs. non-home officers unfolds. As Figure 6 shows, during the first part of the career (up to 16 years), promotions (and hence payscales) in the IAS are primarily mechanically determined by the years of service. In the later part of their careers, however, delays in promotions are more frequent, with senior positions becoming increasingly thinner. At the same time, a merit based component is introduced through review committees. The combination of promotion delays and subjectivity in assessment thus opens room for greater discretion in the selection process.

To study individual-level heterogeneity across career stages, we flexibly estimate the reduced form home state effect (comparing only vs. multiple candidate brackets) by seniority. We do so by binning the years of tenure into the seniority groups associated with each of the seven payscales. Specifically, we split the overall tenure period into seven bins that mirror the time-based payscale progression: 1-3 years (Payscale 1), 4-8 years (Payscale 2), 9-12 years (Payscale 3), 13-15 years (Payscale 4), 16-24 years (Payscale 5), 25-29 years (Payscale 6 ), and more than 30 years (Payscale 7 ).

The resulting estimates are shown in Figure 7, Panel A. The figure shows the crosssectional relationship between the ability to withstand illegitimate political pressure and the years into the IAS. ${ }^{17}$ The estimates are derived from an augmented specification of (2) where we allow the reduced form effect of home allocations to vary by the payscale bins. The negative performance difference between home-allocated officers vs. non-home officers increases with seniority. The performance difference is negative through most of the

\footnotetext{
${ }^{17}$ These results are also reported in Appendix Table B9 in regression form. Appendix Figure A7 shows the results by seniority for all subjective performance measures.
} 
payscales and drops markedly after a brief uptick in the fifth payscale, which corresponds to 16-25 years of tenure. The negative effect is largest towards the end of the career, where IAS officers compete over promotions to the highest payscale. ${ }^{18}$

Of course, a limitation in the cross-sectional setting is that we cannot separately identify seniority from cohort effects. We can address such concerns by leveraging panel data from the personnel records and revisiting suspensions as an alternative measure of (non)performance. Figure 7, Panel B shows the differential suspension probability between home vs. non-home officers (in reduced form) by seniority. Despite the small number of suspension events, the observed pattern is consistent with the cross-sectional result: while there is almost no difference in suspension rates for the bulk of the career, home officers are substantially more likely to be suspended than non-home officers in the highest payscale (after more than 30 years of tenure). Given the low number of overall suspensions, however, the estimate is noisy and statistically insignificant.

We complement our subjective performance and suspension measures with another measure of career performance: serving in Delhi. IAS officers can be empaneled to serve in Delhi at the additional secretary, joint secretary and secretary-level. Allowing IAS officers to serve in Delhi is meant to create national cohesion and maintain the connection between the federal and state-level administration. Since the assignment of officers to states is fixed for life, moving to Delhi is one of the few channels through which officers can leave their assigned state. ${ }^{19}$ Delhi postings require a performance review, are prestigious and therefore viewed as gauges of how well an officer is doing within the service (Iyer and Mani 2012, Ferguson and Hasan 2013). Since all officers go through the review process but officers can choose to take up a Delhi posting if selected, the "in Delhi" is a combined measure of performance and attachment to the allocated state. As Figure 7, Panel C shows, home state officers are less likely to serve in Delhi throughout their career. As for the case of performance in the prior two panels, the gap opens up over time and is largest in the highest payscale.

Finally, in Panel D of Figure 7, we plot the gap in the payscales of home vs. non-home officers throughout the different payscale bins. Remarkably, despite their lower performance, as measured by the subjective performance scores, the higher suspension rate and the lower likelihood of empanelment to Delhi, home state officers tend to be promoted at a higher rate than non-home officers in the same stage of their career. The gap opens up as the timebased promotion becomes less binding due to the delays at higher levels, and is largest for those who served more than 30 years. This negative correlation between the performance and promotion differences across payscales is striking: the promotion gap between home vs. non-home officers is highest in career stages where the negative performance difference is largest. The correlation between the promotion and performance gap, for example, is -0.86 ; the correlation between promotions and suspensions is 0.87 .

The sharp contrast between Panels A, B, C and Panel D of Figure 7 is remarkable.

\footnotetext{
${ }^{18}$ The negative main effects in Table 6 are not driven by the last payscale. There remains a large and statistically significant negative difference when dropping the 285 officers with more than 30 years of tenure.

${ }^{19}$ IAS officers can also request to serve on temporary deputations in other states. Permanent moves are only possible for marriages to another IAS officer. These cases are rare and approved on a case-by-case basis.
} 
One way to interpret this contrast is by considering two paths for IAS officers. One path emphasizes performance, probity and national service while the second path emphasizes local embeddedness, personal gain and state service. The combined evidence in Figure 7 would then suggest that home officers are more likely to go down the latter path. Indeed, home officers perform worse on the subjective and objective performance metrics but are nonetheless favored with earlier promotion. These home officers also are more likely to remain in their home state rather than move to the central government, either because of (negative) performance or due to the greater benefits in remaining in their home state.

It is striking that these gaps between home and non-home officers are particularly large in those later career stages where one expects the role of discretion in the promotion of IAS officers to be more pronounced. This added discretion in the later career stages may open room for patronage and capture by the local political elite. The combined patterns in Figure 7 could hence be viewed as a reflection of home officers being more susceptible to this capture. We conclude the paper by providing corroborating evidence that supports this interpretation. In particular, we focus on the interaction between IAS officers and Chief Ministers to investigate differential patterns of political interference.

\section{Home state allocation and political turnover}

At independence, India adopted the Whitehall model of bureaucracy, which emphasizes the need for the separation between the polity and the bureaucracy, particularly as regards to non-interference of politicians in the postings of bureaucrats. In this model, "civil servants would not be moved or replaced after a change of government, and new ministers would nearly always be expected to work with the officials inherited from their predecessor - even if he or she was from a different political party." "Politicians would be allowed almost no appointments or patronage" with "decisions on professional advancement being made by other civil servants, not by politicians" (Wilson and Barker 1995, p. 131). However, as Iyer and Mani (2012) already demonstrated, there is evidence of de facto political interference in the Indian bureaucracy, with political turnover in a state coinciding with increased reallocation of IAS officers across job postings.

We extend these earlier results and assess if these patterns of political interference are more pronounced for home versus non-home officers, and if within-state proximity between an incoming or outgoing Chief Minister and an IAS officer - as measured by both individuals coming from the same home district - affects the probability of officers being transferred, promoted or demoted. To study this, we exploit the frequent turnovers of Chief Ministers following state elections, which are asynchronous and occur in five-year intervals in India. We move beyond the yearly panel used in Section 4.2 to construct a high frequency monthly balanced panel of IAS officers whom we observe for a six-month window around the month of a Chief Minister appointment. The resulting dataset contains 192 turnovers for 1,785 officers. These correspond to 11,410 IAS officer-turnover events. 


\subsection{Chief Minister turnover, transfers and promotions by seniority}

We first use a simple event study design to see how transfer and promotion rates change in the months around the Chief Minister transition. We estimate for the IAS officer $i$, the Chief Minister transition $j$ and the month around the transition $t$,

$$
y_{i j t}=\Sigma_{k=-6}^{6} \beta_{k} 1[t=k]+\theta_{i j}+\tau_{m(t)}+\varepsilon_{i j t}
$$

where $t=0$ denotes the month of the Chief Minister transition and $t=\{-6,-5, \ldots 5,6\}$ denotes the months around the turnover event. Since six-month windows might overlap when a state experiences several Chief Minister turnovers in short succession, we create balanced individual-month panels for each Chief Minister transition by "stacking" the individualturnover events. Since the stacking implies that there might be "duplicate" individuals for overlapping turnover windows, we only exploit within individual officer $\times$ turnover event window variation, as implemented using the $\theta_{i j}$ fixed effects. $\tau_{M(j, t)}$ is the year-month fixed effect, where $m=M(j, t)$ returns the year-month of the transition event $j$ at time $t$. The $\beta_{k}$ dummies estimate averages for each of the months around the promotion window $k=\{-6,-5 \ldots 5,6\}$. The reference month is the month before the actual turnover, $t-1$.

The result is summarized in Figure 8 for transfers and promotions. The transfer rate surges in the immediate months of the Chief Minister transition. This also coincides with a surge in the promotion rate. To assess the magnitude of the overall transfer surge more precisely, we code a dummy that is 1 in the month of and month after the Chief Minister is appointed (the dummy is 1 for $t=\{0,1\}$ ). The results are reported in Table 8 . In the first two months of a Chief Minister appointment, the transfer probability is $2.5 \%$ points higher than in other months (Column 1). Relative to the mean transfer rate of $12.6 \%$, this corresponds to an increase of $20 \%$. This surge is consistent with political interference: in Column 2, we allow the impact of a new Chief Minister appointment to vary by whether the turnover coincided with a change in the political party or a change in the Chief Minister. The result suggests that the surge in transfers is driven by political party turnover (Column 2). In Column 3, we include senior as a dummy that is 1 if the officer has served for at least 16 years in the IAS. Officers who have served for at least 16 years belong to the "supertime scale" and occupy executive positions at the top of the bureaucracy; this experience threshold also roughly coincides with the median years of experience among active officers. As Column 3 shows, the increase in transfer after political turnover is more pronounced among senior officers.

In the remaining columns of Table 8, we assess how these patterns differ between home and non-home officers. For these more demanding triple interactions, we replace the $\theta_{i j}$ fixed effects with the same rich set of controls as in specification (2). As Table 8, Column 4 shows, the higher transfer rate among senior officers is even more pronounced when these officers are from the state, as captured using the instrument in reduced form. Senior home officers are on average reshuffled more frequently, but even more so when the Chief Minister turns over. Junior home state officers, in contrast, are reshuffled less when a new Chief Minister arrives. These patterns are further shown in Figure 9, where we flexibly estimate 
the differential transfer rate at the time of a new Chief Minister appointment by the years in the IAS. While home state officers see slightly lower transfer rates during a political transition in the junior career stages, the pattern reverses significantly in the senior stages.

Most importantly, the higher transfers also coincide with greater promotions for senior home state officers (Table 8, Column 5). Senior home state officers are more likely to be promoted in the immediate months of a Chief Minister appointment. These senior levels correspond to the career stages where promotions become less time-based (Figure 6) and delays in promotions become more prevalent. As shown in Column 5, these also appear to be the career stages when home state officers have an edge as a new political leader comes in. Finally, Column 6 of Table 8 shows that the patterns in Column 5 are not mechanically related to the higher odds for home state officers to still be in the state (rather than Delhi - see Panel $\mathrm{C}$ of Figure 7) in those later career stages.

\subsection{Within-state analysis: home district proximity and promotions}

Our analysis so far has been confined to the comparison between home state and non-home state officers. Since most Chief Ministers hail from the state they serve, the implicit premise of the event study has been that home state-allocated officers are more likely to be connected to the Chief Minister than non-home officers. Given the sheer size of many Indian states, however, such a broad measure of social proximity might mask substantial heterogeneity.

We thus conclude our analysis by exploiting within-home state variation in social proximity. Indeed, existing work has demonstrated that home district favoritism is an important determinant for resource allocation (Do et al. 2017, Fisman et al. 2017). We leverage our descriptive rolls, which allow us to identify the home districts of all IAS officers. We also read through biographies and public records to identify the home districts of all 132 Chief Ministers in our study period 1980-2011. Combining both data sources allows us to derive a measure of home district proximity between the bureaucrat and the politician that varies both among bureaucrats from the home state and across time depending on which Chief Minister is in power. The key identifying variation stems from the fact that the same home state-allocated officer will face different Chief Ministers throughout his or her career: some Chief Ministers will originate from the same home district within the state while others will come from further away home districts. Since geographical distance is correlated with a host of socioeconomic distances, we use the physical distance between the home district of the Chief Minister and the home district of the home state-allocated IAS officer as a within state measure of social proximity. ${ }^{20}$ Intuitively, we ask whether promotion patterns differ among home officers who originate from the same home district as the incoming Chief Minister versus home officers who do not gain a home district tie with the incoming Chief Minister. We implement this test by augmenting the event study (3), allowing the main

\footnotetext{
${ }^{20}$ We geocode district locations using the Google Maps API based on each district's headquarter. Of course, home state officers are mechanically more likely to originate from closer to the Chief Minister's home district throughout their career than non-home officers. On average, the distance between a Chief Minister's home district and the home district of a home-allocated IAS officer is 390 miles lower than vis-a-vis a non-home state officer (Table 5, Column 3).
} 
effects to vary by an IAS officer and Chief Minister turnover-specific measure of social proximity, same_home $i j$. Conditional on the sample of home state officers, we estimate:

$$
y_{i j t}=\Sigma_{k=-6}^{6}\left(\beta_{k} 1[t=k]+\gamma_{k} 1[t=k] \times s a m e \_h o m e_{i j}\right)+\theta_{i j}+\tau_{t}+\varepsilon_{i j t}
$$

where the specification follows (4) except that we allow the monthly impacts around the turnover event $\gamma_{k}$ to vary by whether the home state officer $i$ becomes home connected in the turnover event $j$. Specifically, same_home $e_{i j}$ is a dummy that is 1 if the officer $i$ did not share the same home district with the outgoing Chief Minister but subsequently became home connected with the incoming Chief Minister. The dummy is 0 if the officer did not experience a switching in connection.

We use a conservative cut-off and define a Chief Minister and bureaucrat to originate from the same home district if their home districts are less than 25 miles apart. ${ }^{21}$ In the context of India with its sizeable states and districts and sprawling agglomerations of connected towns this definition is close enough to capture actual social proximity as regional elites are well connected at this level of geographical proximity. With the 25 miles cut-off, 127 of the 507 home officers ever become home district connected to a Chief Minister throughout their career. With officers often experiencing multiple switches throughout their life-long service, we obtain 212 officer-turnover specific switches. As the Appendix B12 shows, our results do not critically hinge on the 25 miles cut-off but are robust to both more restrictive and more generous definitions of home connectedness, such as using 15 miles, 50 miles, 75 miles or 100 miles cut-offs.

Table 9 reports the results and confirms that home connections are key for promotions. The surge in transfers following a Chief Minister appointment is magnified for those home officers who experience a switch into sharing the same home district as the incoming Chief Minister (Table 9, Column 1). While the point estimate is large, the interaction term however is insignificant. In Columns 2-4, we break down the overall transfers by differentiating between promotions and demotions. Consistent with Chief Ministers exercising favoritism, promotions following a Chief Minister turnover are disproportionately concentrated among those officers who share the same home district (Column 2). While the promotion probability increases by $0.7 \%$ points for those who do not experience a switch in their home ties, that probability increases by an additional $2.6 \%$ points for those who gain a home tie to their Chief Minister. Figure 10 shows this differential promotion probability visually by plotting the monthly averages around the Chief Minister transition for the officers who become home connected and those who do not. While there is no difference in the promotion probability between both groups before the arrival of the new Chief Minister, there is an immediate surge in the promotion probability for those who gain a home connection.

\footnotetext{
${ }^{21}$ Since the identification relies on switches in home connectedness, there is an empirical trade-off when deciding how to define home district connectedness. If the cut-off distance for home district connectedness is too close, there will be too few cases where Chief Ministers and officers actually become home connected. The chances of coming from the exact same narrowly defined home district and experiencing a switch is low. In contrast, if the cut-off distance is too far, we may not be capturing any relevant effects as the physical measure of proximity no longer approximates social proximity.
} 
The effects are asymmetric: Column 3 includes an additional dummy that is 1 if the home state officer was home district-connected to the outgoing Chief Minister but subsequently lost the home tie as a new Chief Minister turned in. If the effect of home ties were symmetric, losing the home tie would lead to a lower promotion rate or even demotion after the home tie is severed. Switching out, however, has no impact on promotion rates (Column 3). Column 4 studies the impacts of the turnover on demotion rates. While demotions increase overall after a Chief Minister transition, the demotion probability is lower for officers who become home connected. Once again, the effect is asymmetric. If anything, losing the home connection further decreases the chances of being demoted. This asymmetry - where gaining connections increases the promotion prospects and shields an officer from demotions, whereas losing connections does not have the opposite impact - provides a channel via which cumulative preferment by Chief Ministers from the same home district can lead to the observed divergence in the promotion paths between home and non-home state officers (Figure 7). It also helps to explain the dissonance between performance and promotion observed for home officers. Despite being perceived as being both more corrupt and less able to withstand illegitimate political pressure, home officers are nonetheless being favored in promotion decisions by incoming politicians. Favoritism in promotion decisions as revealed by the monthly CM turnover panel thus goes hand in hand with the lower performance measures of the IAS officer survey.

There might still be a concern that physical proximity - even if narrowly defined as is in this context - need not indicate social proximity. To alleviate this concern, Column 5 repeats the exercise using caste proximity as an alternative measure of social proximity. Caste politics is a salient feature in India (Iyer and Mani 2012), and belonging to the same caste as the incoming Chief Minister might likewise increase one's promotion odds. Given that $71 \%$ of the officers are classified as unreserved caste (GEN), the group is too large and heterogeneous. Our analysis thus focuses on the reserved castes, which we can divide into OBC, SC, and ST, reflecting the classification used in the IAS. We conducted additional biographical research to classify Chief Ministers and then create dummies that denote whether an IAS officer gains or loses a same caste connection around a Chief Minister transition. The result is reported in Column 5 and is consistent with the home district result: officers who gain a caste connection to the incoming Chief Minister are more likely to be promoted than those who do not become caste connected. Once again, the impact is asymmetric, with switching out not leading to a slowdown in progression.

\section{Conclusion}

Bureaucrats are an important determinant of state capacity. The question of how to recruit and motivate them has thus sparked a vibrant literature on the selection and incentives of public servants (Ashraf and Bandiera 2017, Dal Bo et al. 2013, Dal Bo et al. 2017, Khan et al. 2015). Yet, how to allocate already selected talent has remained an understudied margin for improving public sector performance. In this paper, we ask if allocating bureaucrats to the places they originate from would enhance or depress their performance. All centralized 
bureaucracies face the question of whether to allow officers to serve their home localities.

We make progress by combining detailed institutional knowledge with unique data to study the Indian Administrative Service - the senior-most civil service and "steel frame" of India. We isolate a rare, rule-based source of variation that governs the assignment of officers across India. Linking this variation in home assignment to a large survey on the performance of IAS officers, as well as to rich administrative data from their training academy, allows us to study the performance effects on the allocation margin.

We exploit two layers of social proximity to answer the question of whether or not home allocations affect performance. Our first layer of evidence reveals that home-allocated officers are perceived to be more corrupt and less able to withstand illegitimate political pressure. This average effect masks substantial heterogeneity: when we study state-level heterogeneity in the home allocation effects, we find that the negative effects are primarily driven by the more corrupt states. In these states the pressure for native officers to bend to the politicians may be greater, as might be the opportunities for private gain. Furthermore, we find that the negative effects are most pronounced in the later career stages, the same career stages where we also show that home officers enjoy greater promotion prospects.

The second layer of evidence exploits the Chief Minister turnover to help understand a mechanism through which home state officers might become captured by local politicians. We find that officers that share the same home district as the incoming Chief Minister receive a preferential treatment in promotions. This deeper layer of social proximity is thus predictive of being favored by the incoming politician even within the set of home-allocated officers. Taken together, our results from these two layers of analysis suggest that social proximity hampers bureaucrat performance by facilitating political capture and corruption.

If we consider two career paths for IAS officers - one path that emphasizes performance, probity and national service, while the second path emphasizes local embeddedness, personal gain and state service - the combined evidence would suggest that home officers, especially in weakly institutionalized environments, are more likely at risk to go down the latter path.

These findings complement the growing literature that studies how social proximity affects the performance of individuals in private organizations (Fisman et al. 2017, Fisman et al. 2018, Bandiera et al. 2009). By combining variation in the life-long deployment of officers to states with the exposure to different politicians over time, we bridge the literature on the determinants of bureaucrat performance (Bertrand et al. 2018, Rasul and Rogger 2017) with the literature exploiting political turnover to identify favoritism and patronage (Xu 2018, Jia 2017, Brollo et al. 2017, Colonelli et al. 2018, Akthari et al. 2017).

The results also have resonance for a whole host of less developed countries that are in the process of building state capacity (Besley and Persson 2009). In these contexts, assigning officers back to environments which they are most socially proximate with may actually limit their ability to effectively serve the nation. This is an interesting result, as we know that such home avoidance rules run counter to the preferences of the officers themselves. While related research has suggested that rewarding performance with individually preferred postings may be an effective incentive mechanism (Khan et al. 2018), our results suggest 
that a principal may nonetheless seek to deliberately mismatch officers' preferences and location assignments if their private gains are misaligned with public gains - in this case due to greater likelihood of local capture.

The paper opens up a new direction of research on how to allocate already-recruited talent across a national geography which is separate from the literature on selection and incentives that has dominated the modern literature on bureaucracy. What is exciting about this research is that it suggests that considerable gains in bureaucrat performance (and hence economic performance) may be had from avoiding home allocations without the need for any additional fiscal cost. Indeed, our results indicate that deliberately wrenching bureaucrats away from their preferred home environments is instrumental in ensuring that they place national interests above local and private interests. This points to how central a consideration social proximity should be in attempts to build effective nation states. Not constraining home preferences may prevent an effective and impartial centralized bureaucracy from emerging. History tells us that countries bereft of a coherent and motivated set of bureaucrats who can implement national policies in a coordinated fashion are unlikely to make the transition to industrialized states. More research will be required to identify different pathways to developing effective national bureaucracies - but what is incontrovertible is that there are few issues in the study of state capacity that are more important.

\section{References}

Administrative Reform Commission (2008) "Refurbishing of Personnel Administration Scaling New Heights", Tenth Report, Second Administrative Reforms Commission

Aghion, P. and J. Tirole (1997): "Formal and Real Authority in Organizations" Journal of Political Economy, 105, 1-29

Akthari, M., D. Moreira, D and L. Trucco (2018): "Political Turnover, Bureaucratic Turnover, and the Quality of Public Services", mimeo

Alesina, A. and Reich, B. (2015): "Nation Building”, NBER Working Paper 18839.

Alesina, A. and G. Tabellini (2007): "Bureaucrats or Politicians? Part I: A Single Policy Task", American Economic Review, vol. 97, 169-179.

Amsden, A. (1989): “Asia's Next Giant: South Korea and Late Industrialization", Oxford University Press.

Asher, S. and P. Novosad (2017): "Politics and Local Economic Growth: Evidence from India", American Economic Journal: Applied Economics, vol. 9, 229-273.

Ashraf, N. and O. Bandiera (2017): "Social Incentives in Organizations", Annual Review 
of Economics, vol. 10, 439-463.

Ashraf, N. and O. Bandiera, and Lee S. (2018): "Losing Prosociality in the Quest for Talent? Sorting, Selection, and Productivity", mimeo

Bandiera, O. and Barankay, I. and Rasul, I. (2009): "Social Connections and Incentives in the Workplace: Evidence from Personnel Data", Econometrica, vol. 77 (4), 1047-1094.

Bandiera, O. and Burgess, R., and Deserranno, E., Rasul, I. and Sulaiman, M. (2018): "Social Ties and the Delivery of Development Programs", mimeo

Banks, J. S. and B. R. Weingast (1992): "The Political Control of Bureaucracies under Asymmetric Information", American Journal of Political Science, vol. 36, 509-524.

Bardhan, P. and D. Mookherjee (2006): "Decentralization and Accountability in Infrastructure Delivery in Developing Countries", Economic Journal, vol. 116, 101-127.

Bertrand, M., R. Burgess, A. Chawla, and G. Xu (2018): "The Glittering Prizes: Career Incentives and Bureaucrat Performance", mimeo.

Besley, T. and T. Persson (2009) "The Origins of State Capacity: Property Rights, Taxation and Politics", American Economic Review, vol. 99 (4), 1218-44.

Bhavnani, R. and A. Lee (2018): "Local Embeddedness and Bureaucratic Performance: Evidence from India”, Journal of Politics, vol. 80 (1), 71-87.

Cantor, N. (1993): "Civilization of the Middle Ages: A completely revised and expanded edition of medieval history", Harper Collins.

Casey, K. (2018): "Radical Decentralization: Does community driven development work?", Annual Review of Economics, vol. 10, 139-165.

Colonelli, E. and M. Prem, and E. Teso (2018): "Patronage and Selection in Public Sector Organizations", mimeo

Dal Bo, E. and F. Finan and M.A. Rossi (2013) "Strengthening State Capabilities: The Role of Financial Incentives in the Call to Public Service", Quarterly Journal of Economics, vol. 128 (3), 1169-1218.

Dessein, W. (2002) "Authority and Communication in Organizations", Review of Economic Studies, vol. $69,811-838$. 
Do, Q.-A., and K.-T. Nguyen, and A. N. Tran (2017): "One Mandarin Benefits the Whole Clan: Hometown Favoritism in an Authoritarian Regime", American Economic Journal: Applied Economics, vol. 9 (4), 1-29.

Ebrey, P. and Smith, P. (2016): "State Power in China, 900-1325". University of Washington Press.

Evans, P. (1995): "Embedded Autonomy: States and Industrial Transformation", Princeton University Press.

Finan, F., and B. A. Olken, and R. Pande (2015): "The Personnel Economics of the State", NBER Working Paper 21825.

Fisman, R. and F. Schulz, and V. Vig (2014): "The Private Returns to Public Office", Journal of Political Economy, vol. 122 (4), 806-862.

Fisman, R. and J. Shi and Y. Wang and R. Xu (2018): "Social Ties and Favoritism in Chinese Science", Journal of Political Economy, vol. 126 (3), 1134-1171.

Fisman, R. and D. Paravisini, and V. Vig (2017): "Cultural Proximity and Loan Outcomes", American Economic Review, vol. 107, 457-92.

Greif, A. (2007): "The Impact of Administrative Power on Political and Economic Development: Toward Political Economy of Implementation", mimeo

Huang, Z. L. Li, G. Ma, and L. C. Xu (2017): "Hayek, Local Information, and Commanding Heights: Decentralizing State-Owned Enterprises in China", American Economic Review, vol. 107, 2455-78.

Iyer, L. and A. Mani (2012): "Travelling Agents: Political Change and Bureaucratic Turnover in India", Review of Economics and Statistics, vol. 94, 723-739.

Jia, R. M. Kudamatsu, and D. Seim (2015): "Political Selection in China: The Complementary Roles of Connections and Performance", Journal of the European Economic Association, vol. 13, 631-668.

Kirk-Greene, A. (2000): “Britain’s Imperial Administrators, 1858-1966”, Palgrave Macmillan.

Mansuri, G. and Rao, V. (2013): "Localizing Development: Does Participation Work?", 
World Bank Policy Research Report.

Moe, T. (2012) "Delegation, Control, and the Study of Public Bureaucracy", In Robert Gibbons and John Roberts, eds. Handbook of Organizational Economics. Princeton University Press.

Mookherjee, D. (2015): "Political Decentralization", Annual Reviews of Economics, 7, 231249.

Newbury, C. (2003): "Patrons, Clients, and Empire: Chieftaincy and Over-rule in Asia, Africa, and the Pacific", Oxford University Press.

Northcote, S. and Trevelyan C. E. (1854) "Report on the Organization of the Permanent Civil Service", House of Commons, Her Majesty's Stationery Office

Rauch, J. E. and Evans, P. B. (2000) "Bureaucratic Structure and Bureaucratic Performance in Less Developed Countries", Journal of Public Economics, vol. 75(1), 49-71.

Ujheyli, G. (2014): "Civil Service Rules and Policy Choices: Evidence from U.S. State Governments", American Economic Journal: Economic Policy, vol. 6 (2), 338-380.

Wade, R. (1990): "Governing the Market: Economic Theory and the Role of Governments in East Asian Industrialization", Princeton University Press.

Weaver, J. (2018): "Jobs for Sale: Bribery and Misallocation in Hiring", mimeo

Weber, M. (1922) "Economy and Society", 4th Edition (republished 1956). Tübingen.

Wilson, G. K. and Barker, A. (1995): "The end of the Whitehall model?", West European Politics, vol. 18 (4), 130-149.

Woolf, G. (2012): “Rome: An Empire's Story”, Oxford University Press.

World Bank (2004): "World Development Report 2004: Making Services Work for Poor People", World Bank.

Xu, G. (2018): "The Costs of Patronage: Evidence from the British Empire", American Economic Review, vol. 108 (11), 3170-98. 
Figure 1: Home state allocation and allocation bracket size

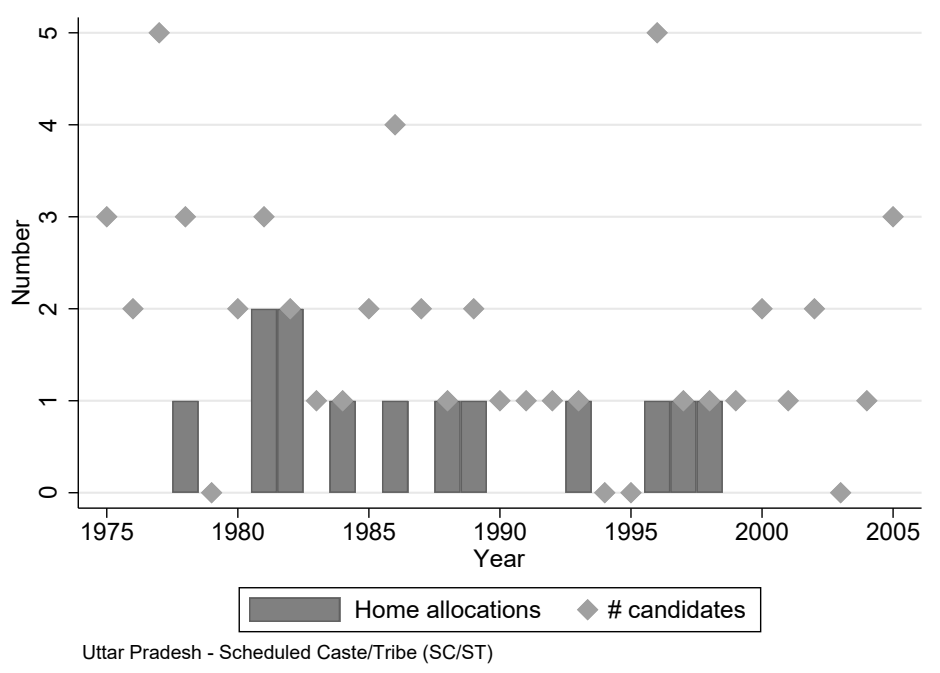

Notes: Bar chart shows the number of home state allocations among Scheduled Castes/Tribes in Uttar Pradesh 1975-2015. Scatter plot shows the number of potential candidates in the home state allocation bracket Uttar Pradesh-Scheduled Castes/Tribes (SC/ST) in a given year of intake.

Figure 2: Predicting home state allocation using allocation bracket size

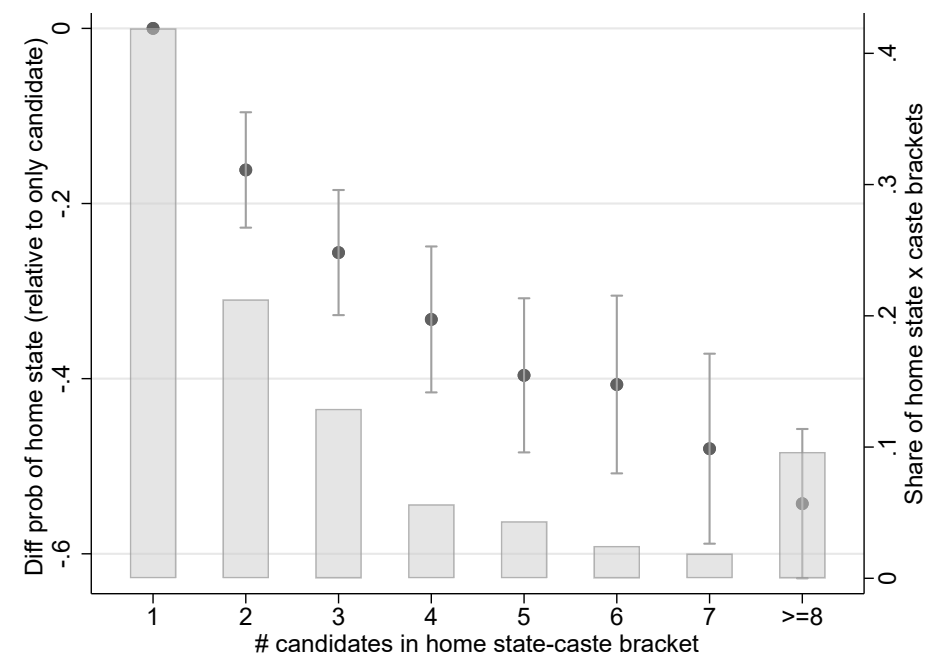

Notes: Relating home state allocation to the number of candidates in the same intake year-home statecaste bracket. Estimates are based on regressing home state allocation on dummies for the number of candidates in the same intake year-home state-caste bracket, intake year FEs and home state $\times$ caste FEs. Estimates show differences relative to being the only candidate. $90 \%$ confidence intervals, with standard errors clustered at the caste-home state-intake year level. 
Figure 3: Home state allocation and only candidate around intake year

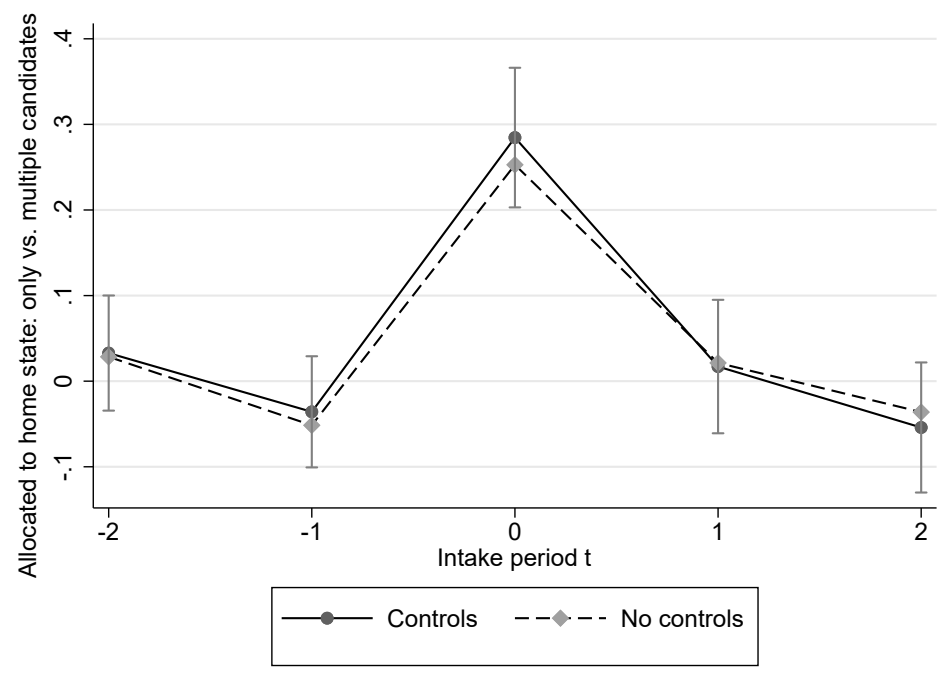

Notes: Relating home state allocation to being the only candidate in the same intake year-home statecaste bracket and the two period leads and lags. The estimates are based on the specification of Table 4, Column 4. The results with no individual-level controls are shown using the dashed line. $90 \%$ confidence intervals based on standard errors clustered at the caste-home state-intake year level.

Figure 4: Home state allocation and ability to withstand illegitimate political pressure

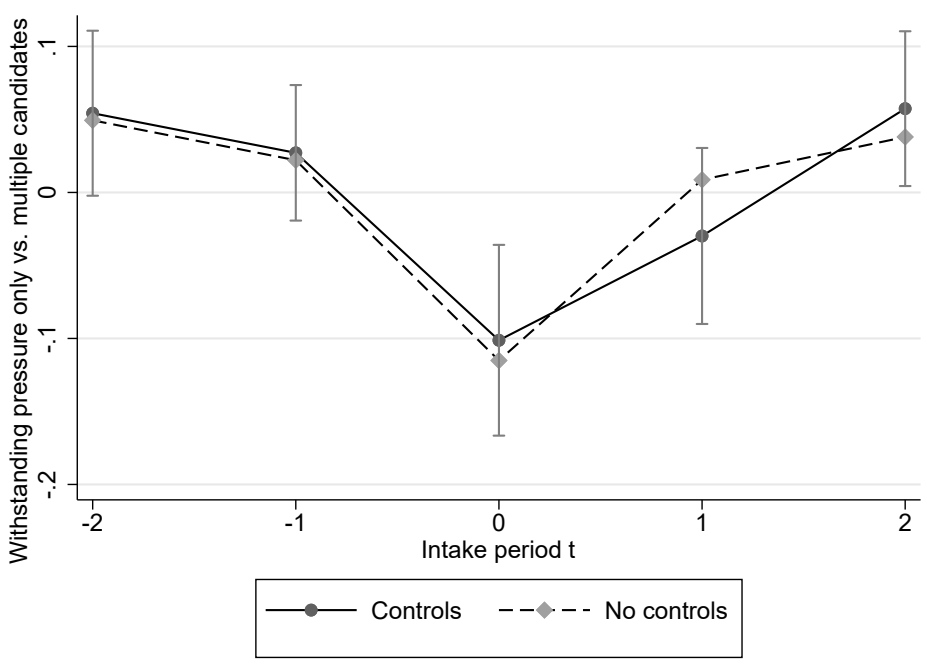

Notes: Relating the perceived ability to withstand illegitimate political pressure to being the only candidate in the same intake year-home state-caste bracket and the two period leads and lags. The estimates are based on the specification of Table 6 . The results with no individual-level controls are reported using the dashed line. 90\% confidence intervals based on standard errors clustered at the caste-home state-intake year and individual IAS officer-level. 
Figure 5: Withstanding pressure and only candidate effect by allocated state

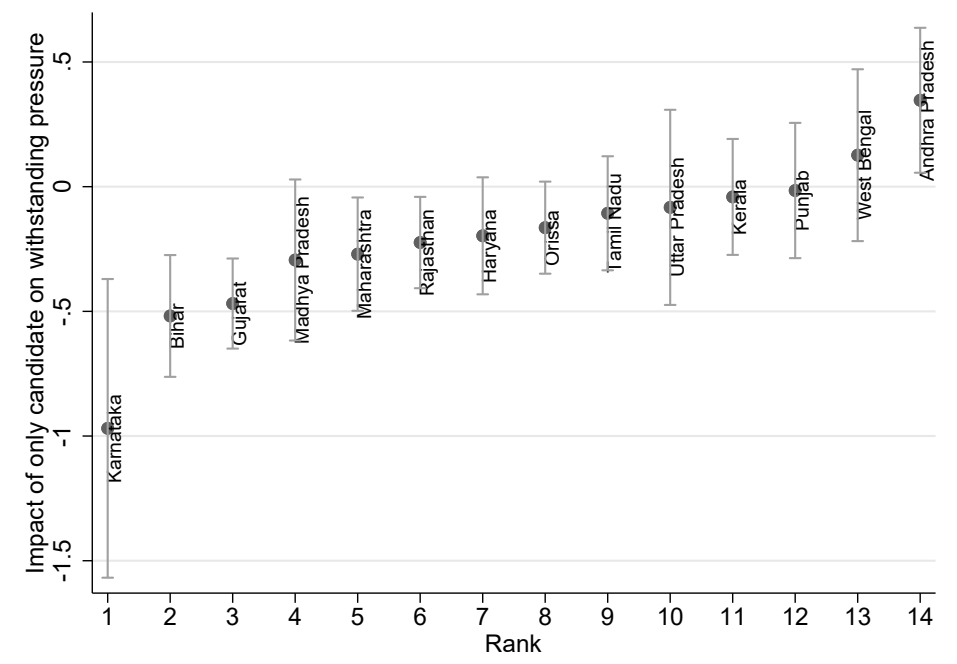

Notes: Reduced form effect of only candidate on the perceived ability to withstand illegitimate political pressure, separately estimated for each major state of India by interacting only candidate $\times$ state dummies. Only candidate is a dummy that is 1 if the IAS officer was the only candidate in the same intake year-home state-caste bracket. 90\% confidence intervals based on standard errors clustered at the caste-home state-intake year and individual IAS officer-level.

Figure 6: Seniority based promotion: Average payscale and years of tenure

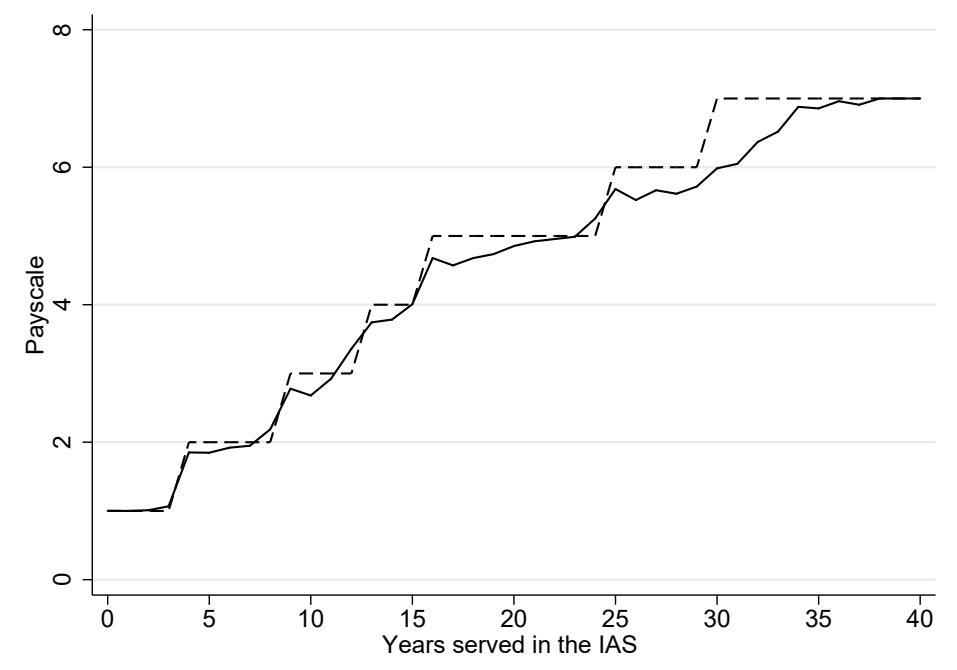

Notes: Average payscale of IAS officers as a function of the years served in the IAS (solid line) for the cross-section of all centrally recruited IAS officers active in 2012. The dashed line marks the payscale as predicted using the IAS promotion guidelines. 
Figure 7: Performance and promotion over the career
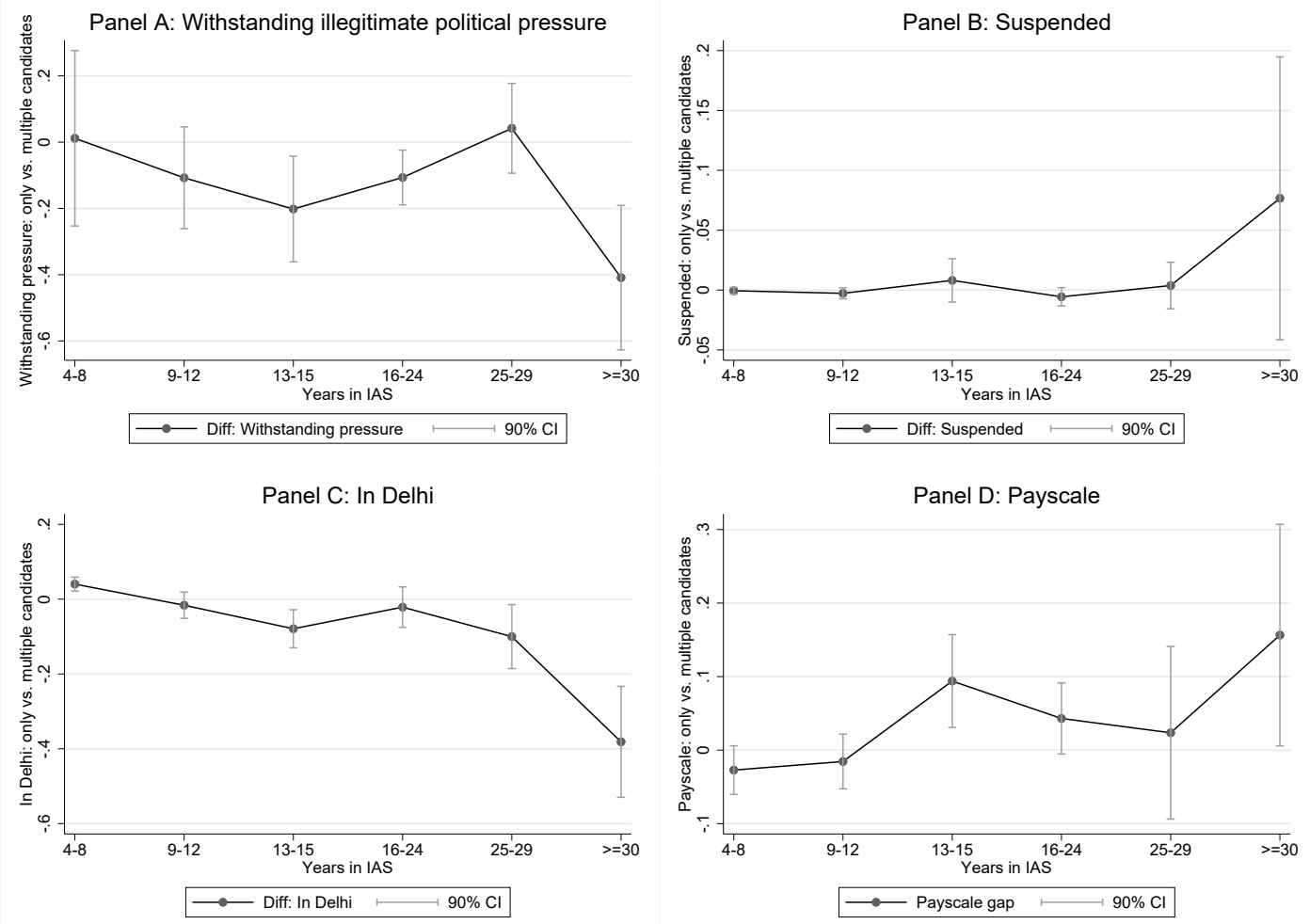

Notes: Differences in performance-related measures (Panels A-C) and promotions (Panel D) between candidates vs. multiple candidates (the reduced form for home vs. non-home candidates) throughout the career, conditional on caste $\times$ home state, year of intake FEs, entry exam rank FEs and background controls. See Appendix Table B9 for the regression tables corresponding to the figures. The dependent variables for each panel are as follows: In Panel A, the dependent variable is the cross-sectional subjective performance measure for the ability to withstand illegitimate political pressure. Panels B-D show career events from an individual-year panel. In Panel B, the dependent variable is a dummy that is 1 if the IAS officer was suspended in a given year (scaled by 100 for readability). In Panel $\mathbf{C}$, the dependent variable is 1 if the IAS officer was serving in Delhi. In Panel $\mathbf{D}$, the dependent variable shows the payscale of an IAS officer, where the payscales range from 1 (lowest) to 7 (highest). The years in IAS are binned to reflect the progression by payscales. $90 \%$ confidence intervals based on standard errors clustered at the caste-home state-intake year and individual IAS officer-level. 
Figure 8: Transfers of IAS officers around Chief Minister appointments

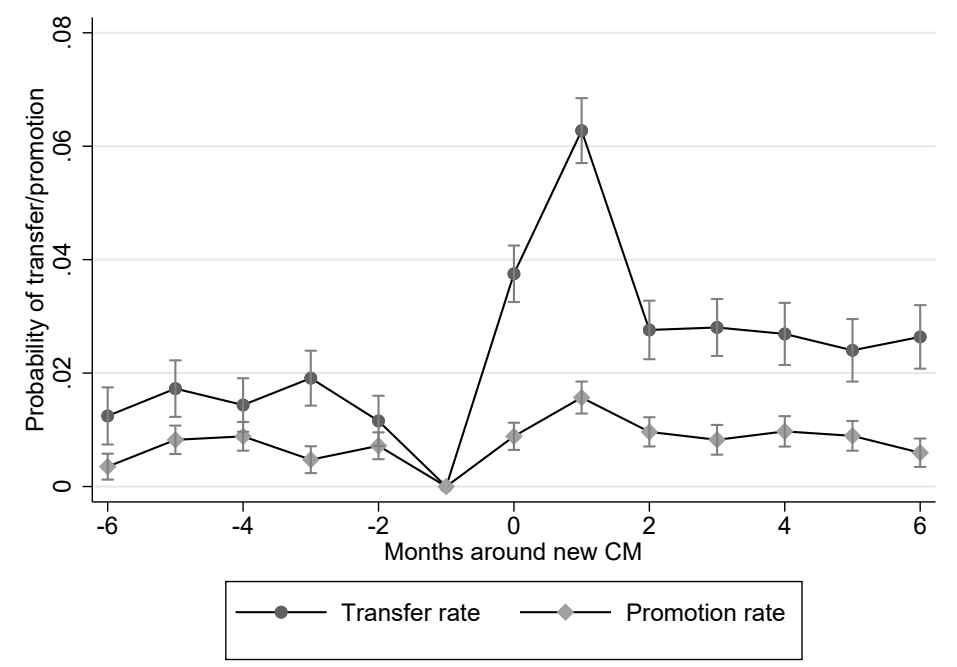

Notes: Transfers and promotions in the months around the appointment of a Chief Minister (centered at $0)$. Balanced sample of IAS officer-Chief Minister transitions around six months windows. All estimates are relative to the month before the Chief Minister transition (-1). 90\% confidence intervals on standard errors clustered at the individual-level. Coefficients reported in Appendix Table B10.

Figure 9: Transfer elasticity for Chief Minister appointments by payscale

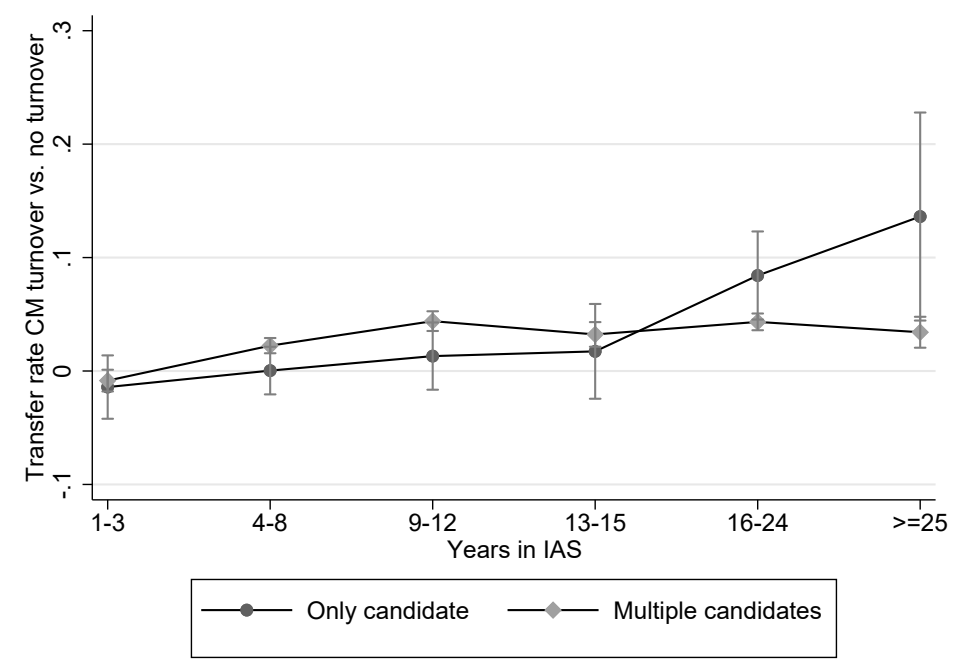

Notes: Balanced sample of IAS officer-Chief Minister transitions around six months windows (see Table 8). Showing the difference in transfer rates in the two months of the Chief Minister appointment $[t, t-1]$ vs. the the other months around the six months window, by seniority. The years into IAS are binned to reflect the progression by payscales. $90 \%$ confidence intervals based on standard errors clustered at the individual-level. Appendix Table B11 reports the coefficients. 
Figure 10: Promotions and home district connectedness to incoming Chief Minister

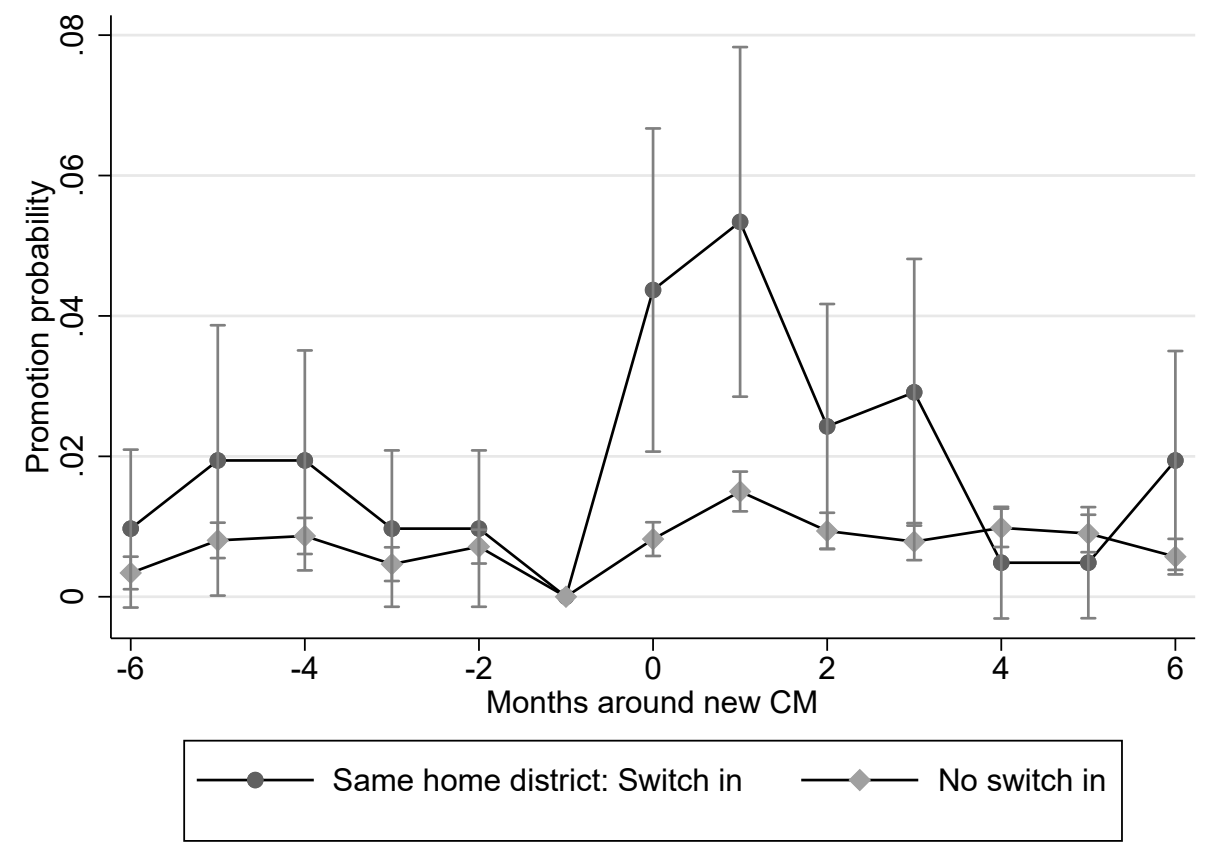

Notes: Balanced sample of IAS officer-Chief Minister transitions around six months windows. Promotion probability for IAS officers who become home district connected to the incoming Chief Minister vs. IAS officers who do not become home district connected. An IAS officer and CM are from the same home district when their home districts are less than 25 miles apart. The event study is based on a balanced panel around the month of the new Chief Minister appointment (marked 0). 90\% confidence intervals based on standard errors are clustered at the individual-level. 
Table 1: Descriptive statistics for the subjective performance scores

\begin{tabular}{lccccc}
\hline \hline & $(1)$ & $(2)$ & $(3)$ & $(4)$ & $(5)$ \\
& Mean & SD & Ratings & Officers & Coverage \\
\hline Withstanding illegitimate pressure & 3.523 & 1.094 & 16,728 & 1,471 & $71.96 \%$ \\
Probity of IAS officer & 3.670 & 1.105 & 15,153 & 1,451 & $70.98 \%$ \\
Effectiveness on the job & 3.730 & 1.077 & 17,753 & 1,472 & $72.01 \%$ \\
Sensitive towards poorer & 3.527 & 1.141 & 17,047 & 1,471 & $71.96 \%$ \\
Overall rating & 3.646 & 1.057 & 17,698 & 1,472 & $72.01 \%$ \\
\hline \hline
\end{tabular}

Notes: Subjective performance scores for the cross-section of rated IAS officers in 2012-13. Reporting the descriptive statistics (mean and standard deviation) for the subjective measures, where the scores range from 1 (lowest) to 5 (highest). Column 3 and 4 report the total number of ratings and the total number of rated officers. Column 5 reports the coverage rate for the sample population of all active, centrally recruited IAS officers with at least 8 years of tenure in 2012/13. 
Table 2: IAS officer characteristics by home state allocation

\begin{tabular}{|c|c|c|c|c|}
\hline \multirow[b]{3}{*}{ Means } & (1) & $(2)$ & $(3)$ & $(4)$ \\
\hline & \multicolumn{2}{|c|}{ Allocation } & \multicolumn{2}{|c|}{ Diff Home-Non-home } \\
\hline & Home & Non-Home & Raw & Within intake \\
\hline Entry (UPSC) exam rank & 44.483 & 56.091 & $\begin{array}{c}-11.607^{* * *} \\
(1.732)\end{array}$ & $\begin{array}{c}-14.959^{* * *} \\
(1.791)\end{array}$ \\
\hline Female & 0.107 & 0.134 & $\begin{array}{l}-0.027 \\
(0.017)\end{array}$ & $\begin{array}{l}-0.020 \\
(0.017)\end{array}$ \\
\hline Urban background & 0.728 & 0.722 & $\begin{array}{c}0.006 \\
(0.022)\end{array}$ & $\begin{array}{l}-0.002 \\
(0.023)\end{array}$ \\
\hline Age at entry & 25.443 & 25.704 & $\begin{array}{c}0.261^{* *} \\
(0.112)\end{array}$ & $\begin{array}{l}-0.022 \\
(0.108)\end{array}$ \\
\hline Distinction & 0.326 & 0.322 & $\begin{array}{c}0.004 \\
(0.024)\end{array}$ & $\begin{array}{c}0.006 \\
(0.024)\end{array}$ \\
\hline STEM or Economics & 0.590 & 0.616 & $\begin{array}{l}-0.025 \\
(0.025)\end{array}$ & $\begin{array}{l}-0.004 \\
(0.025)\end{array}$ \\
\hline Other Backward Caste (OBC) & 0.059 & 0.119 & $\begin{array}{c}-0.059^{* * *} \\
(0.015)\end{array}$ & $\begin{array}{c}-0.024^{*} \\
(0.012)\end{array}$ \\
\hline Scheduled Caste (SC) & 0.168 & 0.116 & $\begin{array}{c}0.052^{* * *} \\
(0.017)\end{array}$ & $\begin{array}{c}0.061^{* * *} \\
(0.019)\end{array}$ \\
\hline Scheduled Tribe (ST) & 0.078 & 0.059 & $\begin{array}{c}0.019 \\
(0.012)\end{array}$ & $\begin{array}{c}0.022 \\
(0.014)\end{array}$ \\
\hline Previous job: Education/Research & 0.173 & 0.147 & $\begin{array}{c}0.026 \\
(0.018)\end{array}$ & $\begin{array}{l}-0.007 \\
(0.019)\end{array}$ \\
\hline Previous job: Finance/Banking & 0.055 & 0.049 & $\begin{array}{c}0.006 \\
(0.011)\end{array}$ & $\begin{array}{l}-0.002 \\
(0.012)\end{array}$ \\
\hline Previous job: None & 0.294 & 0.299 & $\begin{array}{c}0.005 \\
(0.023)\end{array}$ & $\begin{array}{c}0.010 \\
(0.023)\end{array}$ \\
\hline Previous job: Private/SOE & 0.114 & 0.118 & $\begin{array}{l}-0.003 \\
(0.016)\end{array}$ & $\begin{array}{c}0.008 \\
(0.017)\end{array}$ \\
\hline Previous job: Public & 0.326 & 0.345 & $\begin{array}{l}-0.018 \\
(0.024)\end{array}$ & $\begin{array}{c}0.003 \\
(0.025)\end{array}$ \\
\hline Previous job: Public - AIS & 0.034 & 0.039 & $\begin{array}{l}-0.005 \\
(0.009)\end{array}$ & $\begin{array}{l}-0.012 \\
(0.009)\end{array}$ \\
\hline Cohort size & 7.685 & 6.306 & $\begin{array}{c}1.379^{* * *} \\
(0.200)\end{array}$ & $\begin{array}{c}1.003^{* * *} \\
(0.388)\end{array}$ \\
\hline Caste fractionalization & 0.326 & 0.344 & $\begin{array}{l}-0.017 \\
(0.011)\end{array}$ & $\begin{array}{c}0.025 * * \\
(0.011)\end{array}$ \\
\hline Intake year FEs & - & - & - & $\mathrm{Y}$ \\
\hline Diff jointly zero: $p$-value & & & $0.000 * * *$ & $0.000 * * *$ \\
\hline Observations & 542 & 1,326 & 1,888 & 1,888 \\
\hline
\end{tabular}

Notes: Unit of observation is the IAS officer. Columns 1-2 show the mean characteristics for those who received the home allocation and those who did not. Column 3 is the raw difference in means between home and non-home allocated officers. Column 4 shows the mean difference among officers of the same intake year. UPSC Rank is the entry exam (UPSC) rank in the intake year. Female is a dummy that is 1 if the IAS officer is female. Urban background is a dummy that is 1 if the IAS officer is from an urban background. Age at entry is the entry age of the officer. Distinction is a dummy that is 1 if the IAS officer received an academic distinction. STEM is a dummy that is 1 if the IAS officer studied a STEM or Economics degree. Previous job: are categories for the previous positions the IAS officer held before entering IAS. Cohort size is the total number of officers allocated to same state in same year. Caste fractionalization is the fractionalization index for the cohort based on the caste categories. Robust standard errors. ${ }^{*} p<0.1,{ }^{* *} p<0.05,{ }^{* * *} p<0.01$. 
Table 3: IAS officer characteristics by allocation bracket size (one vs. many candidates)

\begin{tabular}{|c|c|c|c|c|}
\hline \multirow[b]{3}{*}{ Means } & \multirow{2}{*}{\multicolumn{2}{|c|}{$\begin{array}{c}(1) \\
\text { Candidates in bracket }\end{array}$}} & \multirow{2}{*}{\multicolumn{2}{|c|}{$\begin{array}{l}(4) \\
\text { Diff Only-Many }\end{array}$}} \\
\hline & & & & \\
\hline & Only (1) & Many $(>1)$ & Raw & Within bracket \\
\hline Entry (UPSC) exam rank & 61.39 & 51.82 & $\begin{array}{c}9.569^{* * *} \\
(2.584)\end{array}$ & $\begin{array}{l}-1.741 \\
(1.990)\end{array}$ \\
\hline Female & 0.178 & 0.121 & $\begin{array}{c}0.056^{* *} \\
(0.024)\end{array}$ & $\begin{array}{l}0.067^{*} \\
(0.035)\end{array}$ \\
\hline Urban background & 0.695 & 0.727 & $\begin{array}{c}0.032 \\
(0.032)\end{array}$ & $\begin{array}{c}0.007 \\
(0.039)\end{array}$ \\
\hline Age at entry & 26.507 & 25.524 & $\begin{array}{c}0.982^{* * *} \\
(0.159)\end{array}$ & $\begin{array}{c}0.061 \\
(0.205)\end{array}$ \\
\hline Distinction & 0.352 & 0.320 & $\begin{array}{l}-0.032 \\
(0.034)\end{array}$ & $\begin{array}{c}0.044 \\
(0.043)\end{array}$ \\
\hline STEM or Economics & 0.594 & 0.610 & $\begin{array}{l}-0.016 \\
(0.035)\end{array}$ & $\begin{array}{c}0.006 \\
(0.045)\end{array}$ \\
\hline Previous job: Education/Research & 0.111 & 0.160 & $\begin{array}{l}-0.049^{*} \\
(0.026)\end{array}$ & $\begin{array}{c}0.013 \\
(0.028)\end{array}$ \\
\hline Previous job: Finance/Banking & 0.043 & 0.051 & $\begin{array}{l}-0.008 \\
(0.016)\end{array}$ & $\begin{array}{l}-0.005 \\
(0.020)\end{array}$ \\
\hline Previous job: None & 0.294 & 0.298 & $\begin{array}{l}-0.003 \\
(0.039)\end{array}$ & $\begin{array}{l}-0.016 \\
(0.041)\end{array}$ \\
\hline Previous job: Private/SOE & 0.111 & 0.118 & $\begin{array}{c}0.007 \\
(0.023)\end{array}$ & $\begin{array}{c}0.004 \\
(0.032)\end{array}$ \\
\hline Previous job: Public & 0.415 & 0.330 & $\begin{array}{l}0.084^{* *} \\
(0.034)\end{array}$ & $\begin{array}{l}-0.011 \\
(0.046)\end{array}$ \\
\hline Previous job: Public - AIS & 0.024 & 0.039 & $\begin{array}{l}-0.015 \\
(0.014)\end{array}$ & $\begin{array}{c}0.014 \\
(0.015)\end{array}$ \\
\hline Cohort size & 5.115 & 7.093 & $\begin{array}{c}-1.977^{* * *} \\
(0.293)\end{array}$ & $\begin{array}{c}0.149 \\
(0.264)\end{array}$ \\
\hline Caste fractionalization & 0.425 & 0.330 & $\begin{array}{c}0.094^{* * *} \\
(0.015)\end{array}$ & $\begin{array}{c}0.004 \\
(0.017)\end{array}$ \\
\hline Intake year FEs & - & - & - & $\mathrm{Y}$ \\
\hline Home state-Caste FEs & - & - & - & $\mathrm{Y}$ \\
\hline Diff jointly zero: $p$-value & & & $0.000^{* * *}$ & 0.831 \\
\hline Observations & 207 & 1,681 & 1,888 & 1,882 \\
\hline
\end{tabular}

Notes: Unit of observation is the IAS officer. Columns 1-2 show the mean characteristics for those who are the only candidate in the intake year-home state-caste bracket. Column 3 is the raw difference in means between those who are only candidates and those with many candidates in the intake year-home state-caste bracket. Column 4 shows the mean difference among officers of the same intake year and within the same home state-caste bracket. UPSC Rank is the entry exam (UPSC) rank in the intake year. Female is a dummy that is 1 if the IAS officer is female. Urban background is a dummy that is 1 if the IAS officer is from an urban background. Age at entry is the entry age of the officer. Distinction is a dummy that is 1 if the IAS officer received an academic distinction. STEM is a dummy that is 1 if the IAS officer studied a STEM or Economics degree. Previous job: are categories for the previous positions the IAS officer held before entering IAS. Cohort size is the total number of officers allocated to same state in same year. Caste fractionalization is the fractionalization index for the cohort based on the caste categories. Standard errors clustered at the caste-home state-intake year level. $* p<0.1, * *$ $p<0.05$, *** $p<0.01$. 
Table 4: Predicting home state assignment with allocation rule

\begin{tabular}{|c|c|c|c|c|}
\hline \multirow[b]{3}{*}{ Mean of dep. var } & (1) & $(2)$ & $(3)$ & (4) \\
\hline & \multicolumn{4}{|c|}{ Allocated to home state } \\
\hline & 0.277 & 0.277 & 0.277 & 0.285 \\
\hline Only candidate $t+2$ & & & & $\begin{array}{c}0.033 \\
(0.041)\end{array}$ \\
\hline Only candidate $t+1$ & & & & $\begin{array}{l}-0.036 \\
(0.039)\end{array}$ \\
\hline Only candidate & $\begin{array}{c}0.228^{* * *} \\
(0.042)\end{array}$ & $\begin{array}{c}0.241^{* * *} \\
(0.046)\end{array}$ & $\begin{array}{c}0.250^{* * *} \\
(0.046)\end{array}$ & $\begin{array}{c}0.285^{* * *} \\
(0.050)\end{array}$ \\
\hline Only candidate $t-1$ & & & & $\begin{array}{c}0.017 \\
(0.047)\end{array}$ \\
\hline Only candidate $t-2$ & & & & $\begin{array}{l}-0.054 \\
(0.046)\end{array}$ \\
\hline Intake year FEs & $\bar{Y}$ & $\bar{Y}$ & $\bar{Y}$ & $\mathrm{Y}$ \\
\hline Home state $\times$ Caste FEs & Y & $\mathrm{Y}$ & $\mathrm{Y}$ & $\mathrm{Y}$ \\
\hline Rank FEs & - & $\mathrm{Y}$ & $\mathrm{Y}$ & $\mathrm{Y}$ \\
\hline Individual controls & - & - & $\mathrm{Y}$ & $\mathrm{Y}$ \\
\hline Observations & 1,880 & 1,868 & 1,868 & 1,700 \\
\hline
\end{tabular}

Notes: Unit of observation is the IAS officer. Relating home state allocation to the instrument. The instrument only candidate is a dummy that is 1 if the IAS officer was the only candidate in the intake yearhome state-caste bracket. Individual controls are: entry exam score, entry exam rank fixed effects for each rank in the entry exam, age at entry, female dummy, a dummy for coming from an urban background, having received an academic distinction, a STEM or Economics degree, dummies for previous job type. Standard errors clustered at the caste-home state-intake year level. ${ }^{*} p<0.1,{ }^{* *} p<0.05,{ }^{* * *} p<0.01$. 
Table 5: Social proximity and home state allocation

\begin{tabular}{|c|c|c|c|}
\hline Mean of dep. var & $\begin{array}{c}(1) \\
\text { Distance } \\
\text { home district } \\
455.5\end{array}$ & $\begin{array}{c}(2) \\
\text { Same } \\
\text { language } \\
0.388 \\
\end{array}$ & $\begin{array}{c}(3) \\
\text { Dist. home } \\
\text { CM } 2012 \\
494.4 \\
\end{array}$ \\
\hline \multicolumn{4}{|l|}{ Panel A: OLS } \\
\hline Home state & $\begin{array}{c}-482.150^{* * *} \\
(16.116)\end{array}$ & $\begin{array}{c}0.692^{* * *} \\
(0.022)\end{array}$ & $\begin{array}{c}-438.06^{* * *} \\
(18.549)\end{array}$ \\
\hline \multicolumn{4}{|l|}{ Panel B: IV } \\
\hline Home state & $\begin{array}{c}-495.720^{* * *} \\
(87.548)\end{array}$ & $\begin{array}{c}0.829 * * * \\
(0.130)\end{array}$ & $\begin{array}{c}-389.27^{* * *} \\
(105.60)\end{array}$ \\
\hline Kleibergen-Paap $F$-statistic & 34.000 & 29.836 & 27.854 \\
\hline Intake year FEs & $\mathrm{Y}$ & $\mathrm{Y}$ & $\mathrm{Y}$ \\
\hline Home state $\times$ Caste FEs & $\mathrm{Y}$ & $\mathrm{Y}$ & $\mathrm{Y}$ \\
\hline Rank FEs & $\mathrm{Y}$ & $\mathrm{Y}$ & $\mathrm{Y}$ \\
\hline Individual controls & $\mathrm{Y}$ & $\mathrm{Y}$ & $\mathrm{Y}$ \\
\hline Observations & 1,625 & 1,868 & 1,497 \\
\hline
\end{tabular}

Notes: Unit of observation is the IAS officer. Relating measures of social proximity to home state allocation. Home state is a dummy that is 1 if the officer was allocated to his or her state of permanent domicile. The instrument only candidate is a dummy that is 1 if the IAS officer was the only candidate in the intake year-home state-caste bracket. Panel A presents the OLS estimates. Panel B presents the IV results. Distance to home district is the distance (in miles) between the allocated state's state capital and the officer's home district. Same language is a dummy that is 1 if the IAS officer's mother tongue is the first official language in the state. Distance between the IAS officer's home district and the home district of Chief Ministers serving in 2012 is measured by the distance (in miles) between the district headquarters. Individual controls are: entry exam score, entry exam rank fixed effects for each rank in the entry exam, age at entry, female dummy, a dummy for coming from an urban background, having received an academic distinction, a STEM or Economics degree, dummies for previous job type. Standard errors clustered at the caste-home state-intake year level. ${ }^{*} p<0.1,{ }^{* *} p<0.05,{ }^{* * *} p<0.01$. 
Table 6: Subjective performance ratings and home state allocation

\begin{tabular}{lccccc}
\hline \hline & $(1)$ & $(2)$ & $(3)$ & $(4)$ & $(5)$ \\
& Pressure & Probity & Effective & Pro-poor & Overall \\
Mean of dep. var & 3.524 & 3.671 & 3.730 & 3.528 & 3.647 \\
\hline Panel A: OLS & & & & & \\
Home state & -0.001 & 0.005 & 0.007 & 0.020 & $0.050^{*}$ \\
& $(0.026)$ & $(0.030)$ & $(0.026)$ & $(0.027)$ & $(0.029)$ \\
\hline Panel B: IV & & & & & \\
Home state & $-0.381^{* * *}$ & $-0.202^{*}$ & -0.034 & -0.112 & -0.103 \\
& $(0.121)$ & $(0.119)$ & $(0.107)$ & $(0.113)$ & $(0.127)$ \\
Kleibergen-Paap F-stat & 46.495 & 56.885 & 46.470 & 45.626 & 46.168 \\
\hline Home state $\times$ Caste FEs & $\mathrm{Y}$ & $\mathrm{Y}$ & $\mathrm{Y}$ & $\mathrm{Y}$ & $\mathrm{Y}$ \\
Intake year FEs & $\mathrm{Y}$ & $\mathrm{Y}$ & $\mathrm{Y}$ & $\mathrm{Y}$ & $\mathrm{Y}$ \\
Respondent FEs & $\mathrm{Y}$ & $\mathrm{Y}$ & $\mathrm{Y}$ & $\mathrm{Y}$ & $\mathrm{Y}$ \\
State $\times$ Tenure FEs & $\mathrm{Y}$ & $\mathrm{Y}$ & $\mathrm{Y}$ & $\mathrm{Y}$ & $\mathrm{Y}$ \\
Individual controls & $\mathrm{Y}$ & $\mathrm{Y}$ & $\mathrm{Y}$ & $\mathrm{Y}$ & $\mathrm{Y}$ \\
Observations & 16,712 & 15,128 & 17,744 & 17,037 & 17,689 \\
\hline \hline
\end{tabular}

Notes: Unit of observation is the score for a given IAS officer in 2012-13 with at least 8 years of tenure. Relating five measures of perceived performance (ability to withstand illegitimate political pressure, probity, effectiveness, pro-poor orientedness and overall rating) to home state allocation. Home state is a dummy that is 1 if the IAS officer is allocated to his or her state of origin. Only candidate is a dummy that is 1 if the IAS officer was the only candidate in the intake year-home state-caste bracket. Panel A presents the OLS estimates. Panel B presents the IV results. Individual controls are: entry exam score, entry exam rank fixed effects for each rank in the entry exam, age at entry, female dummy, a dummy for coming from an urban background, having received an academic distinction, a STEM or Economics degree, dummies for previous job type. Standard errors clustered at the caste-home state-intake year and individual IAS officer level. $* p<0.1,{ }^{* *} p<0.05$, *** $p<0.01$. 
Table 7: Withstanding illegitimate pressure, suspensions and state-level corruption

\begin{tabular}{lcccccc}
\hline \hline & $(1)$ & $(2)$ & $(3)$ & \multicolumn{2}{c}{$(4)$} & \multicolumn{2}{c}{$(5)$} & $(6)$ \\
& \multicolumn{2}{c}{ Withstanding pressure } & \multicolumn{2}{c}{ Index } & \multicolumn{2}{c}{ Suspended } \\
Mean of dep. var & 3.523 & 3.496 & 3.496 & 0.000 & 0.833 & 0.833 \\
\hline Only candidate & $-0.136^{* * *}$ & $-0.142^{* * *}$ & $-0.142^{* * *}$ & $-0.119^{* * *}$ & -0.263 & -0.250 \\
& $(0.038)$ & $(0.041)$ & $(0.041)$ & $(0.035)$ & $(0.286)$ & $(0.285)$ \\
$\times$ TI corruption index & & $-0.105^{* * *}$ & $-0.112^{* *}$ & $-0.096^{* *}$ & $0.405^{* *}$ & $0.681^{* *}$ \\
& & $(0.035)$ & $(0.052)$ & $(0.048)$ & $(0.185)$ & $(0.280)$ \\
$\times$ Human Development Index & & & -0.009 & -0.000 & & 0.385 \\
& & & $(0.048)$ & $(0.044)$ & & $(0.279)$ \\
\hline Home state $\times$ Caste FEs & $\mathrm{Y}$ & $\mathrm{Y}$ & $\mathrm{Y}$ & $\mathrm{Y}$ & $\mathrm{Y}$ & $\mathrm{Y}$ \\
State $\times$ Tenure FEs & $\mathrm{Y}$ & $\mathrm{Y}$ & $\mathrm{Y}$ & $\mathrm{Y}$ & $\mathrm{Y}$ & $\mathrm{Y}$ \\
Controls & $\mathrm{Y}$ & $\mathrm{Y}$ & $\mathrm{Y}$ & $\mathrm{Y}$ & $\mathrm{Y}$ & $\mathrm{Y}$ \\
Year FEs & & & & & $\mathrm{Y}$ & $\mathrm{Y}$ \\
Sample & & & Cross-section & & \multicolumn{2}{c}{ Panel } \\
Observations & 16,712 & 15,644 & 15,644 & 12,958 & 31,712 & 31,712 \\
\hline \hline
\end{tabular}

Notes: Unit of observation is the score for a given IAS officer in 2012-13 with at least 8 years of tenure (Columns 1-4) and the IAS officer-year for the time period 1980-2011 (Columns 5-6). Relating the standardized ability to withstand illegitimate political pressure and suspensions to home state allocation. Suspended is a dummy that is 1 (scaled by 100) if the IAS officer was suspended in a given year. Home state is a dummy that is 1 if the IAS officer is allocated to his or her state of origin. The instrument only candidate is a dummy that is 1 if the IAS officer was the only candidate in the intake year-home state-caste bracket. TI corruption index is the state-level Transparency International corruption index from 2005 as used by Fisman et al. (2014). The HDI is the state-level Human Development Index in 2007. Caste FEs are dummies for OBC, SC, ST. Rank FEs are fixed effects for each rank in the entry exam. Individual controls are: entry exam score, age at entry, female dummy, a dummy for coming from an urban background, having received an academic distinction, a STEM or Economics degree, dummies for previous job type. Standard errors clustered at the caste-home state-intake year and individual IAS officer level. ${ }^{*} p<0.1,{ }^{* *} p<0.05,{ }^{* * *} p<0.01$. 
Table 8: Transfers, promotions and Chief Minister turnover by home state allocation

\begin{tabular}{|c|c|c|c|c|c|c|}
\hline \multirow[b]{3}{*}{ Mean of dep. var } & (1) & $(2)$ & (3) & (4) & $(5)$ & (6) \\
\hline & \multicolumn{4}{|c|}{ IAS officer was transferred } & \multicolumn{2}{|c|}{ Promoted } \\
\hline & 0.126 & 0.126 & 0.126 & 0.126 & 0.0231 & 0.0243 \\
\hline Chief Minister appointed $[t, t-1]$ & $\begin{array}{c}0.025^{* * *} \\
(0.002)\end{array}$ & $\begin{array}{l}-0.004 \\
(0.005)\end{array}$ & $\begin{array}{c}0.020^{* * *} \\
(0.003)\end{array}$ & $\begin{array}{c}0.025^{* * *} \\
(0.003)\end{array}$ & $\begin{array}{c}0.008^{* * *} \\
(0.002)\end{array}$ & $\begin{array}{c}0.009^{* * *} \\
(0.002)\end{array}$ \\
\hline$\times$ Party switch & & $\begin{array}{c}0.059^{* * * *} \\
(0.005)\end{array}$ & & & & \\
\hline$\times$ CM switch & & $\begin{array}{c}0.007 \\
(0.006)\end{array}$ & & & & \\
\hline$\times$ Senior & & & $\begin{array}{c}0.017^{* * * *} \\
(0.005)\end{array}$ & $\begin{array}{c}0.004 \\
(0.006)\end{array}$ & $\begin{array}{c}-0.010^{* * *} \\
(0.003)\end{array}$ & $\begin{array}{c}-0.008^{* * *} \\
(0.003)\end{array}$ \\
\hline$\times$ Only candidate & & & & $\begin{array}{c}-0.020^{* *} \\
(0.009)\end{array}$ & $\begin{array}{l}-0.007 \\
(0.004)\end{array}$ & $\begin{array}{c}-0.008^{*} \\
(0.005)\end{array}$ \\
\hline$\times$ Senior $\times$ Only candidate & & & & $\begin{array}{c}0.042^{* *} \\
(0.020)\end{array}$ & $\begin{array}{c}0.020^{* *} \\
(0.010)\end{array}$ & $\begin{array}{l}0.023^{*} \\
(0.012)\end{array}$ \\
\hline Senior $\times$ Only candidate & & & & $\begin{array}{c}0.047^{* *} \\
(0.022)\end{array}$ & $\begin{array}{l}-0.001 \\
(0.007)\end{array}$ & $\begin{array}{c}0.002 \\
(0.009)\end{array}$ \\
\hline Year $\times$ Month FEs & $\mathrm{Y}$ & $\mathrm{Y}$ & $\mathrm{Y}$ & $\mathrm{Y}$ & $\mathrm{Y}$ & $\mathrm{Y}$ \\
\hline IAS officer $\times$ Turnover event FEs & $\mathrm{Y}$ & $\mathrm{Y}$ & $\mathrm{Y}$ & & & \\
\hline Controls & & & & $\mathrm{Y}$ & $\mathrm{Y}$ & $\mathrm{Y}$ \\
\hline Sample & & & Full sampl & & & No Delhi \\
\hline Observations & 148,330 & 148,330 & 148,330 & 148,330 & 148,330 & 127,934 \\
\hline
\end{tabular}

Notes: Unit of observation is the IAS officer-month. Balanced sample of IAS officer-Chief Minister transitions around six months windows of Chief Minister appointments. Relating transfers and career progression to Chief Minister appointments. Transfer is a dummy that is 1 if the IAS officer was transferred in a given month. Promoted, demoted, lateral are dummies that denote whether a transfer was upward, downwards or in the same payscale. Chief Minister appointed is a dummy that is 1 in the month the Chief Minister is appointed as well as the month after $([t, t+1])$. Party switch is a dummy that is 1 if the turnover involved a switch in the political party. $C M$ switch is a dummy that is 1 if the turnover involved a change in the Chief Minister. Senior is a dummy that is 1 if the IAS officer is at least 16 years in service. Only candidate is a dummy that is 1 if the IAS officer was the only candidate in the intake year-home state-caste bracket. The controls are : Home state $\times$ Caste FEs (Caste FEs are dummies for OBC, SC, ST); year of intake FEs; only candidate, senior dummy, entry exam score, entry exam rank fixed effects for each rank in the entry exam, age at entry, female dummy, a dummy for coming from an urban background, having received an academic distinction, a STEM or Economics degree, dummies for previous job type. Column 6 restricts the sample to only officers who are not in Delhi. Standard errors clustered at the individual IAS officer level. ${ }^{*} p<0.1,{ }^{* *} p<0.05,{ }^{* * *} p<0.01$. 
Table 9: Turnover and home district connectedness to the Chief Minister

\begin{tabular}{|c|c|c|c|c|c|}
\hline \multirow[b]{3}{*}{ Mean of dep. var } & $(1)$ & $(2)$ & $(3)$ & $(4)$ & $(5)$ \\
\hline & Transfer & \multicolumn{2}{|c|}{ Promoted } & Demoted & Promoted \\
\hline & 0.129 & 0.0235 & 0.0235 & 0.00409 & 0.0236 \\
\hline Chief Minister appointed $[t, t-1]$ & $\begin{array}{c}0.025^{* * *} \\
(0.004)\end{array}$ & $\begin{array}{c}0.007^{* * *} \\
(0.002)\end{array}$ & $\begin{array}{c}0.007^{* * *} \\
(0.002)\end{array}$ & $\begin{array}{c}0.002^{* * *} \\
(0.001)\end{array}$ & $\begin{array}{c}0.004 \\
(0.003)\end{array}$ \\
\hline$\times$ Home connected: Switch in & $\begin{array}{c}0.034 \\
(0.023)\end{array}$ & $\begin{array}{c}0.026^{* *} \\
(0.012)\end{array}$ & $\begin{array}{c}0.026^{* *} \\
(0.012)\end{array}$ & $\begin{array}{c}-0.005^{*} \\
(0.003)\end{array}$ & \\
\hline$\times$ Home connected: Switch out & & & $\begin{array}{l}-0.000 \\
(0.010)\end{array}$ & $\begin{array}{c}-0.003^{* * *} \\
(0.001)\end{array}$ & \\
\hline$\times$ Same caste: Switch in & & & & & $\begin{array}{c}0.023^{* *} \\
(0.011)\end{array}$ \\
\hline$\times$ Same caste: Switch out & & & & & $\begin{array}{l}-0.009 \\
(0.011)\end{array}$ \\
\hline Year $\times$ Month FEs & $\mathrm{Y}$ & $\mathrm{Y}$ & $\mathrm{Y}$ & $\mathrm{Y}$ & $\mathrm{Y}$ \\
\hline IAS officer $\times$ Turnover event & $\mathrm{Y}$ & $\mathrm{Y}$ & $\mathrm{Y}$ & $\mathrm{Y}$ & $\mathrm{Y}$ \\
\hline Sample & & Home st & te officers & & Lower caste \\
\hline Observations & 46,947 & 46,947 & 46,947 & 46,947 & 32,573 \\
\hline
\end{tabular}

Notes: Unit of observation is the IAS officer-month. Balanced sample of IAS officer-Chief Minister transitions around six months windows of Chief Minister appointments. Relating transfers, promotions, demotions and lateral moves to social connections with the incoming Chief Minister. Chief Minister appointed is a dummy that is 1 in the month the Chief Minister is appointed as well as the month after $([t, t+1])$. An IAS officer and Chief Minister are defined as home connected if their home districts are less than 25 miles apart. Home connected: Switch in is a dummy that is 1 if the officer moved from not being home connected to home connected. Home connected: Switch out is a dummy that is 1 if the officer moved from home connected to not being home connected. An IAS officer and Chief Minister are defined as being from the same caste if their caste status is both OBC, both SC, or both ST. Same caste: Switch in is a dummy that is 1 if the officer moved from not being caste connected to being caste connected. Same caste: Switch out is a dummy that is 1 if the officer moved from being caste connected to caste unconnected. For Columns 1-4, the sample is restricted to home state officers only. For Column 5 , the sample is restricted to reserved caste $(\mathrm{OBC} / \mathrm{SC} / \mathrm{ST})$ officers only. Standard errors clustered at the individual IAS officer level. ${ }^{*} p<0.1,{ }^{* *} p<0.05,{ }^{* * *} p<0.01$. 


\section{A Appendix - For Online Publication}

Figure A1: Determination of vacancies: Example 2006

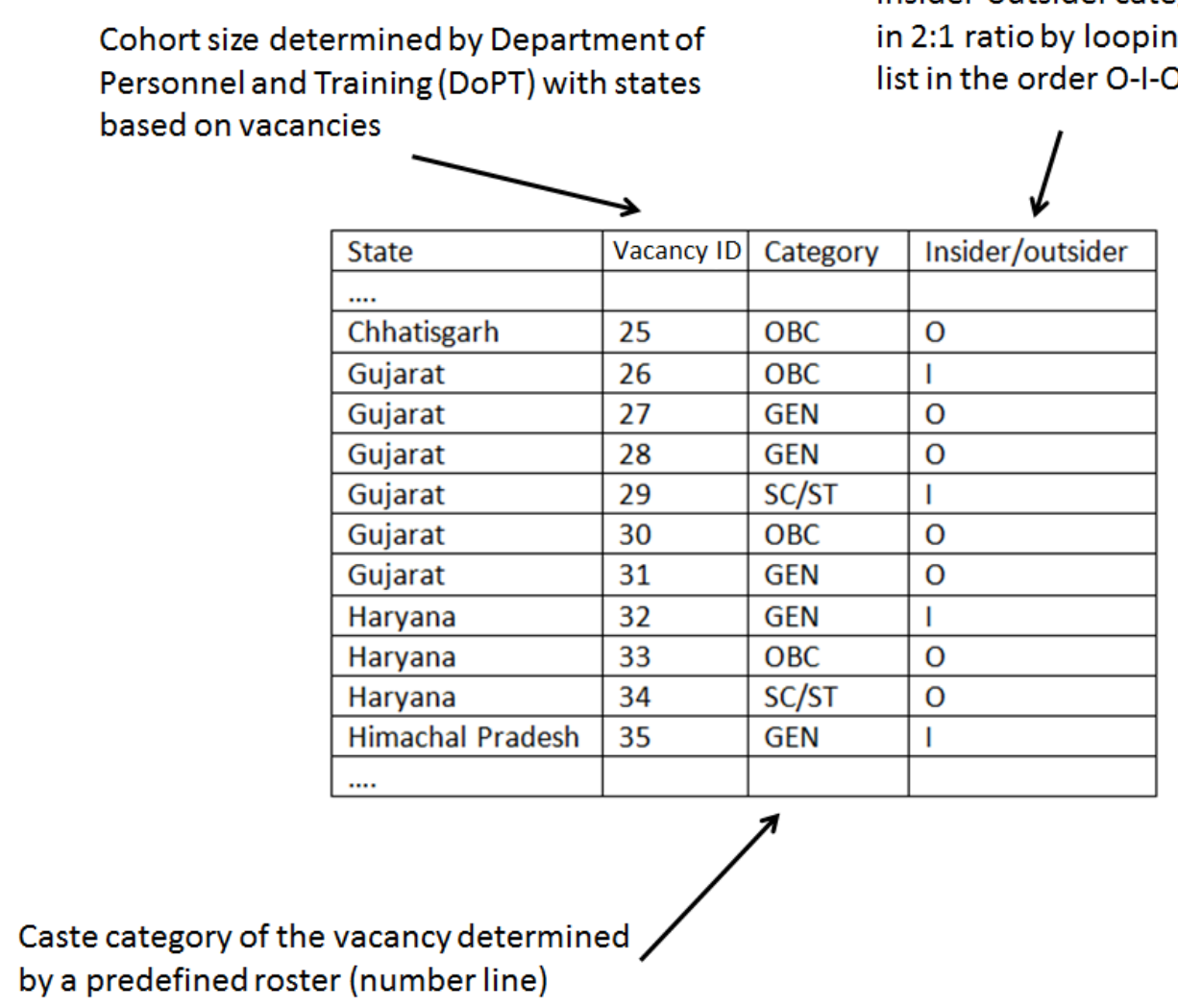

Illustrating the assignment of categories (caste and home preference) to vacancies through the roster randomization for the year 2006. Vacancies are earmarked by caste status (O.B.C. denotes other backward castes, S.C./S.T. scheduled castes/tribes and unreserved the general castes) and home state ("I" denotes insider vacancies reserved for applicants from the same state; "O" denotes outsider vacancies reserved for applicants from other states). The assignment occurs through a number line. 
Figure A2: Assignment of categories (caste and home preference) to vacancies through roster randomization

\section{Cadre Allocation - 2006}

Distribution of vacancies to be filled in various cadres/joint cadres of Indian Administrative Service (IAS) on the basis of Civil Services Examination 2006, among Insider and Outsider Vacancies and between categories.

\begin{tabular}{|c|c|c|c|c|c|c|c|c|}
\hline $\begin{array}{l}\text { SI. } \\
\text { No. }\end{array}$ & $\begin{array}{l}\text { Name of the State } \\
\text { Cadre / Joint Cadre }\end{array}$ & $\begin{array}{l}\text { Unreserved } \\
\text { Insider }\end{array}$ & $\begin{array}{c}\text { Unreserved } \\
\text { Outsider }\end{array}$ & OBC Insider & $\begin{array}{c}\text { OBC } \\
\text { Outsider }\end{array}$ & $\begin{array}{l}\text { SC/ST } \\
\text { Insider }\end{array}$ & $\begin{array}{c}\text { SC/ST } \\
\text { Outsider }\end{array}$ & Total \\
\hline 1 & A G M U T & 1 & 2 & 1 & 0 & 0 & 1 & 5 \\
\hline 2 & Andhra Pradesh & 1 & 1 & 0 & 0 & 0 & 0 & 2 \\
\hline 3 & Assam Meghalaya & 1 & 2 & 0 & 1 & 1 & 0 & 5 \\
\hline 4 & Bihar & 2 & 1 & 0 & 2 & 1 & 1 & 7 \\
\hline 5 & Chhatisgarh & 0 & 3 & 1 & 1 & 1 & 0 & 6 \\
\hline 6 & Gujarat & 0 & 3 & 1 & 1 & 1 & 0 & 6 \\
\hline 7 & Haryana & 1 & 0 & 0 & 1 & 0 & 1 & 3 \\
\hline 8 & Himachal Pradesh & 1 & 0 & 0 & 0 & 0 & 0 & 1 \\
\hline 9 & Jammu \& Kashmir & 0 & 1 & 0 & 0 & 0 & 0 & 1 \\
\hline 10 & Jharkhand & 0 & 1 & 0 & 0 & 0 & 0 & 1 \\
\hline 11 & Karnataka & 0 & 1 & 1 & 0 & 0 & 1 & 3 \\
\hline 12 & Kerala & 1 & 0 & 0 & 1 & 0 & 0 & 2 \\
\hline 13 & Madhya Pradesh & 2 & 1 & 0 & 1 & 0 & 1 & 5 \\
\hline 14 & Maharashtra & 1 & 2 & 0 & 1 & 1 & 0 & 5 \\
\hline 15 & Manipur Tripura & 0 & 3 & 0 & 1 & 1 & 0 & 5 \\
\hline 16 & Nagaland & 0 & 1 & 0 & 1 & 1 & 0 & 3 \\
\hline 17 & Orissa & 1 & 1 & 0 & 1 & 0 & 1 & 4 \\
\hline 18 & Punjab & 0 & 1 & 1 & 0 & 0 & 1 & 3 \\
\hline 19 & Rajasthan & 0 & 1 & 1 & 0 & 0 & 1 & 3 \\
\hline 20 & Sikkim & 0 & 0 & 1 & 0 & 0 & 1 & 2 \\
\hline 21 & Tamil Nadu & 0 & 1 & 1 & 0 & 0 & 0 & 2 \\
\hline 22 & Uttar Pradesh & 1 & 2 & 0 & 2 & 1 & 1 & 7 \\
\hline 23 & Uttaranchal & 1 & 0 & 0 & 1 & 0 & 1 & 3 \\
\hline \multirow[t]{2}{*}{24} & West Bengal & 0 & 3 & 1 & 0 & 0 & 1 & 5 \\
\hline & & 14 & 31 & 9 & 15 & 8 & 12 & 89 \\
\hline
\end{tabular}

The final distribution of vacancies by state and caste/home quota for the year 2006 . Vacancies are earmarked by caste status (O.B.C. denotes other backward castes, S.C./S.T. scheduled castes/tribes and unreserved the general castes) and home state (insider vacancies are reserved for applicants from the same state; outsider vacancies are reserved for applicants from other states). 
Figure A3: Merit-based (UPSC rank) allocation based on caste and home preference match

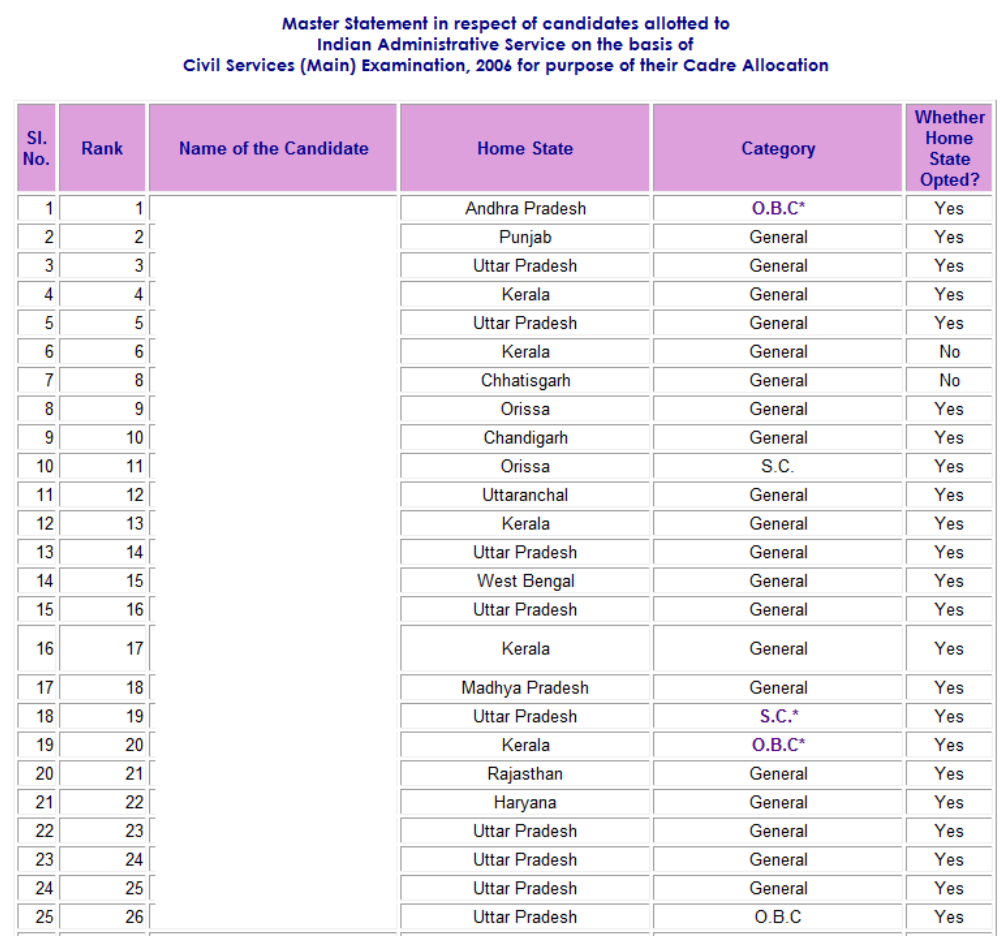

Illustrating the ranking of candidates using the intake year of 2006. The names have been removed in this figure but the full list is publicly available through the Union Public Service Commission. The successful applicants in a given year of intake are ranked in descending order based on the UPSC entry exam score. Home state denotes the state from which the candidate applied from. Category denotes the caste of the candidate, where O.B.C. denotes other backward castes, S.C. scheduled castes, S.T. scheduled tribes and General the unreserved castes. Whether home state opted denotes if the applicant indicated a preference to be allocated to the home state. 
Figure A4: Rotation of state groups over years

\begin{tabular}{|c|}
\hline $\begin{array}{c}\text { Grouping of Cadres to be used } \\
\text { for Cadre Allocation of IAS } \\
\text { Candidates }\end{array}$ \\
\hline Group I \\
\hline $\begin{array}{l}\text { 1. Andhra Pradesh } \\
\text { 2. Assam Meghalaya } \\
\text { 3. Bihar } \\
\text { 4. Chhattisgarh } \\
\text { 5. Gujarat }\end{array}$ \\
\hline Group II \\
\hline $\begin{array}{l}\text { 1. Haryana } \\
\text { 2. Himachal Pradesh } \\
\text { 3. Jammu \& Kashmir } \\
\text { 4. Jharkhand } \\
\text { 5. Karnataka } \\
\text { 6. Kerala } \\
\text { 7. Madhya Pradesh }\end{array}$ \\
\hline Group III \\
\hline $\begin{array}{l}\text { 1. Maharashtra } \\
\text { 2. Manipur Tripura } \\
\text { 3. Nagaland } \\
\text { 4. Orissa } \\
\text { 5.Punjab } \\
\text { 6. Rajasthan } \\
\text { 7. Sikkim }\end{array}$ \\
\hline Group IV \\
\hline $\begin{array}{l}\text { 1.Tamil Nadu } \\
\text { 2. A G M UT } \\
\text { 3. Uttaranchal } \\
\text { 4. Uttar Pradesh } \\
\text { 5. West Bengal }\end{array}$ \\
\hline
\end{tabular}

\begin{tabular}{|c|}
\hline $\begin{array}{l}\text { Order of Groups followed } \\
\text { during Cadre Allocation of IAS } \\
\text { Candidates of CSE } 2006\end{array}$ \\
\hline Group III \\
\hline $\begin{array}{l}\text { 1. Maharashtra } \\
\text { 2.Manipur Tripura } \\
\text { 3. Nagaland } \\
\text { 4. Orissa } \\
\text { 5. Punjab } \\
\text { 6. Rajasthan } \\
\text { 7. Sikkim }\end{array}$ \\
\hline Group IV \\
\hline $\begin{array}{l}\text { 1. Tamil Nadu } \\
\text { 2. A G M UT } \\
\text { 3.Uttaranchal } \\
\text { 4. Uttar Pradesh } \\
\text { 5. West Bengal }\end{array}$ \\
\hline Group I \\
\hline $\begin{array}{l}\text { 1. Andhra Pradesh } \\
\text { 2. Assam Meghalaya } \\
\text { 3. Bihar } \\
\text { 4. Chhattisgarh } \\
\text { 5. Gujarat }\end{array}$ \\
\hline Group II \\
\hline $\begin{array}{l}\text { 1. Haryana } \\
\text { 2. Himachal Pradesh } \\
\text { 3. Jammu \& Kashmir } \\
\text { 4. Jharkhand } \\
\text { 5. Karnataka } \\
\text { 6. Kerala } \\
\text { 7. Madhya Pradesh }\end{array}$ \\
\hline
\end{tabular}

Groups of states rotate each year to ensure states receive on average comparable quality

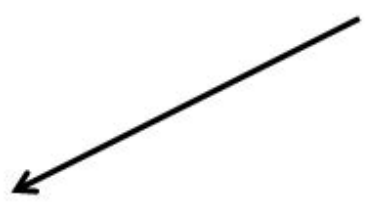

Division of state cadres into four groups and the rotation of groups in the order of IAS officer allocation over time, as illustrated by the group order in 2006. The groups of states rotate each year. In 2007, for example, the order changes to Group II, Group III, Group IV, Group I. 
Figure A5: Subjective performance measures and leads/lags in being the only candidate
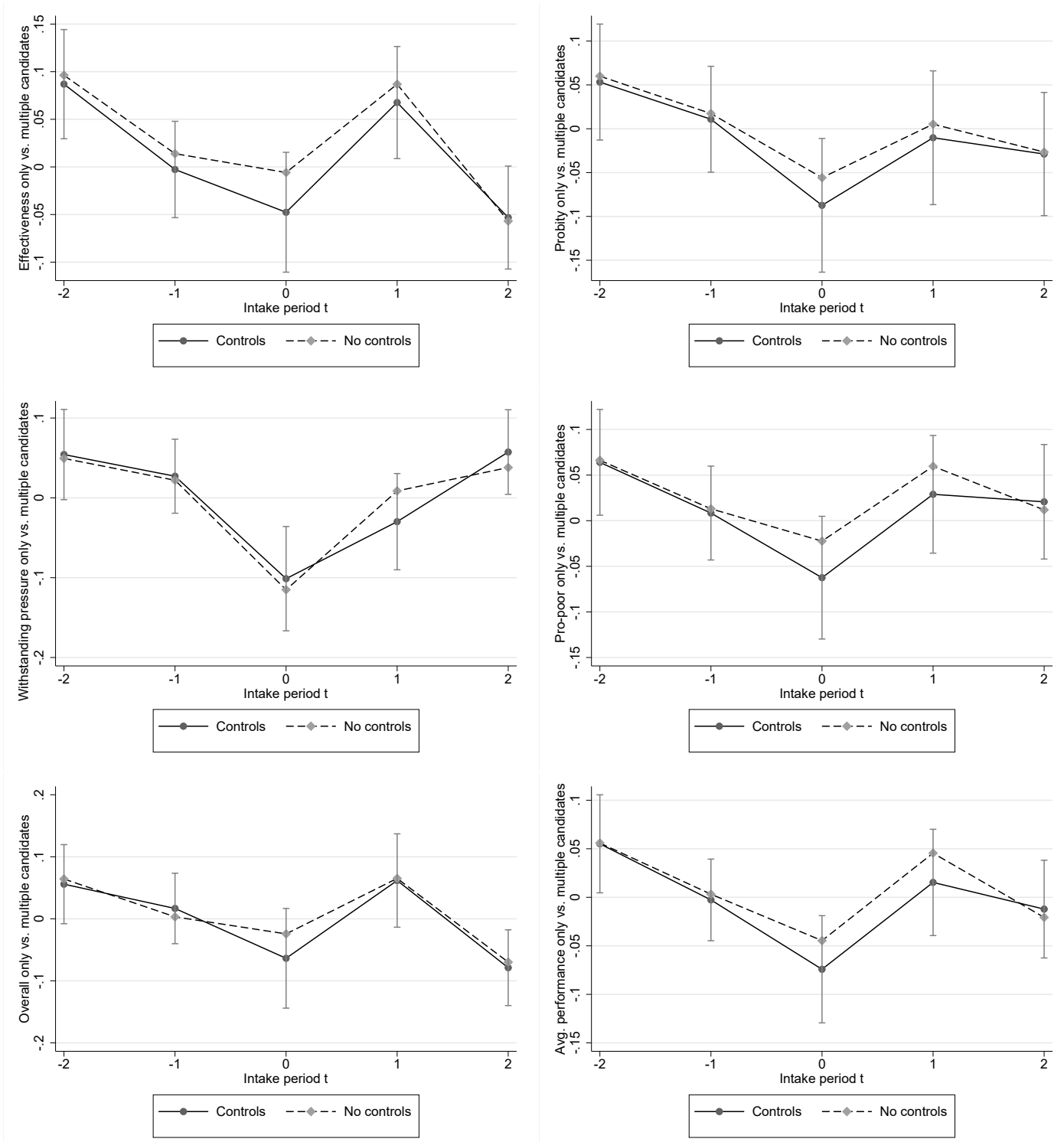

Notes: Relating the subjective performance scores to being the only candidate in the same intake-yearhome state-caste bracket and the two period leads and lags. The estimates are based on the specification of Table 6. The results with no individual-level controls are reported in the dashed line. Showing $90 \%$ confidence intervals based on standard errors clustered at the caste-home state-intake year level. 
Figure A6: Subjective performance measures and being the only candidate by state
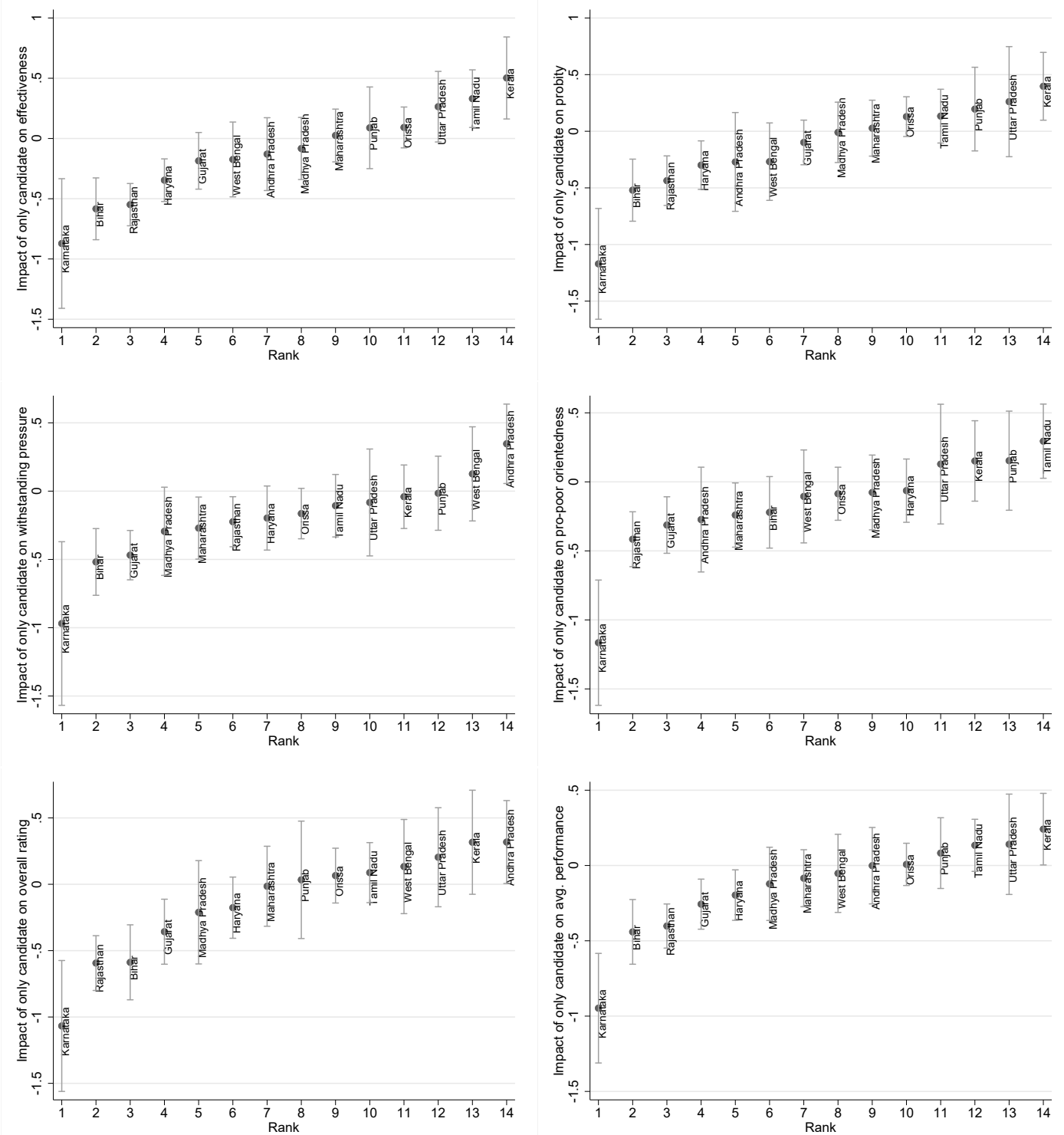

Notes: Relating the subjective performance scores to being the only candidate in the same intake-yearhome state-caste bracket by allocated state. The estimates are based on the specification of Table 6 . Showing $90 \%$ confidence intervals based on standard errors clustered at the caste-home state-intake year level. 
Figure A7: Subjective performance measures over the career
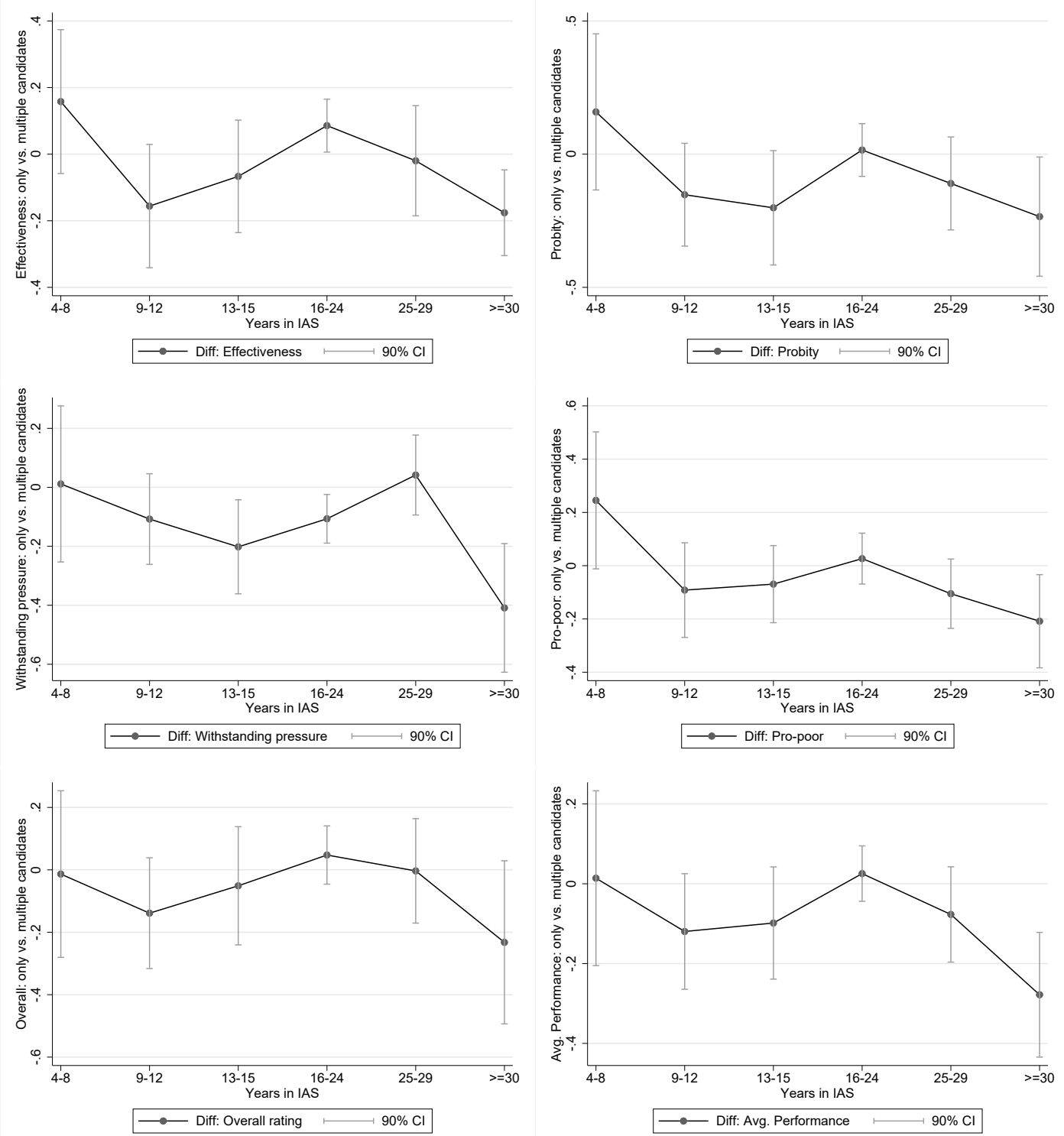

Notes: Difference in the subjective performance scores between only candidates vs. multiple candidates (the reduced form for home vs. non-home candidates) throughout the career, conditional on caste $\times$ home state, year of intake FEs, entry exam rank FEs and background controls. The years in IAS are binned to reflect the progression by payscales. $90 \%$ confidence intervals based on standard errors clustered at the caste-home state-intake year level. 
Table B1: Testing for selective sorting

\begin{tabular}{|c|c|c|c|c|}
\hline & $(1)$ & $(2)$ & $(3)$ & $(4)$ \\
\hline & Number & of recrui & officers & Top 10 \\
\hline Mean of dep. var & 2.005 & 2.005 & 2.005 & 0.128 \\
\hline Total number of vacancies & $\begin{array}{l}-0.049 \\
(0.072)\end{array}$ & $\begin{array}{c}0.044 \\
(0.046)\end{array}$ & & \\
\hline Vacancies reserved for home officers (insider) & & & $\begin{array}{c}-0.025 \\
(0.091)\end{array}$ & $\begin{array}{c}-0.001 \\
(0.023)\end{array}$ \\
\hline Vacancies reserved for outsiders & & & $\begin{array}{c}0.089 \\
(0.105)\end{array}$ & $\begin{array}{c}0.013 \\
(0.014)\end{array}$ \\
\hline Intake year FEs & $\mathrm{Y}$ & $\mathrm{Y}$ & $\mathrm{Y}$ & $\mathrm{Y}$ \\
\hline Home state FEs & $\mathrm{Y}$ & - & - & - \\
\hline Caste FEs & $\mathrm{Y}$ & - & - & - \\
\hline Home state $\times$ Caste FEs & - & $\mathrm{Y}$ & $\mathrm{Y}$ & $\mathrm{Y}$ \\
\hline Observations & 873 & 873 & 873 & 873 \\
\hline
\end{tabular}

Notes: Unit of observation is the intake year - home state - caste bracket. Relating the number of recruited officer and their rank by selection bracket. In Columns 1-3, the dependent variable is the total number of recruited officer from a given intake year - home state - caste bracket. In Column 4, the dependent variable is the number of recruited officers from a given selection bracket who rank within the top 10. The sample covers all IAS entrants between 2005-2016. Total number of vacancies denotes the total number of slots approved in a given intake year for a state and reserved for a caste bracket (General, OBC, SC/ST). Caste FEs are dummies for OBC, SC, ST. Standard errors clustered at the intake year level. ${ }^{*} p<0.1,{ }^{* *} p<0.05,{ }^{* * *} p<0.01$. 
Table B2: State-level correlates of the share of single bracket entrants

\begin{tabular}{lcccc}
\hline \hline & $(1)$ & $(2)$ & $(3)$ & $(4)$ \\
& Share of only candidates & $1975-2005$ \\
Mean of dep. var & 0.214 & 0.214 & 0.214 & 0.214 \\
\hline $\log$ (State level population) & -0.159 & & & -0.188 \\
& $(0.137)$ & & & $(0.136)$ \\
TI corruption index & & -0.034 & & -0.089 \\
& & $(0.042)$ & & $(0.081)$ \\
Human Development Index & & & -0.380 & -1.204 \\
& & & $(0.591)$ & $(1.047)$ \\
\hline Observations & 14 & 14 & 14 & 14 \\
\hline \hline
\end{tabular}

Notes: Unit of observation is the state. Sample comprises the 14 main states of India for which we have collected performance scores. Relating the overall share of single bracket entrants (only candidates) to state-level characteristics. Population count is from the 2011 Census, the TI corruption index is the state-level Transparency International corruption index from 2005 as used by Fisman et al. (2014), and the HDI is the Human Development Index in 2007. Robust standard errors. ${ }^{*} p<0.1,{ }^{* *} p<0.05$, ${ }^{* * *}$ $p<0.01$. 
Table B3: Subjective performance measures and present/past suspensions

\begin{tabular}{|c|c|c|c|c|c|}
\hline Mean of dep. var & $\begin{array}{c}(1) \\
\text { Effective } \\
3.730\end{array}$ & $\begin{array}{c}(2) \\
\text { Probity } \\
3.671\end{array}$ & $\begin{array}{c}(3) \\
\text { Pressure } \\
3.524\end{array}$ & $\begin{array}{c}(4) \\
\text { Pro-Poor } \\
3.528\end{array}$ & $\begin{array}{c}(5) \\
\text { Overall } \\
3.647\end{array}$ \\
\hline \multicolumn{6}{|c|}{ Panel A: Current suspension } \\
\hline Suspended & $\begin{array}{c}-0.388^{* *} \\
(0.152)\end{array}$ & $\begin{array}{c}-0.506^{* * *} \\
(0.183)\end{array}$ & $\begin{array}{c}-0.558^{* * *} \\
(0.156)\end{array}$ & $\begin{array}{c}-0.386^{* *} \\
(0.159)\end{array}$ & $\begin{array}{c}-0.571^{* * *} \\
(0.185)\end{array}$ \\
\hline State $\times$ Intake year FEs & $\mathrm{Y}$ & $\mathrm{Y}$ & $\mathrm{Y}$ & $\mathrm{Y}$ & $\mathrm{Y}$ \\
\hline Respondent FEs & $\mathrm{Y}$ & $\mathrm{Y}$ & $\mathrm{Y}$ & $\mathrm{Y}$ & $\mathrm{Y}$ \\
\hline Observations & 17,749 & 15,133 & 16,717 & 17,042 & 17,694 \\
\hline Mean of dep. var & $\begin{array}{c}(1) \\
\text { Effective } \\
3.730\end{array}$ & $\begin{array}{c}(2) \\
\text { Probity } \\
3.671\end{array}$ & $\begin{array}{c}(3) \\
\text { Pressure } \\
3.524\end{array}$ & $\begin{array}{c}(4) \\
\text { Pro-Poor } \\
3.528\end{array}$ & $\begin{array}{c}(5) \\
\text { Overall } \\
3.647\end{array}$ \\
\hline \multicolumn{6}{|c|}{ Panel B: Past suspensions } \\
\hline Mean past suspensions & $\begin{array}{c}-0.842^{* *} \\
(0.418)\end{array}$ & $\begin{array}{c}-1.195^{* *} \\
(0.589)\end{array}$ & $\begin{array}{c}-0.849^{* * *} \\
(0.326)\end{array}$ & $\begin{array}{c}-0.213 \\
(0.337)\end{array}$ & $\begin{array}{l}-0.768^{*} \\
(0.413)\end{array}$ \\
\hline Respondent FEs & $\mathrm{Y}$ & $\mathrm{Y}$ & $\mathrm{Y}$ & $\mathrm{Y}$ & $\mathrm{Y}$ \\
\hline State $\times$ Intake year FEs & $\mathrm{Y}$ & $\mathrm{Y}$ & $\mathrm{Y}$ & $\mathrm{Y}$ & $\mathrm{Y}$ \\
\hline Observations & 17,750 & 15,138 & 16,719 & 17,043 & 17,695 \\
\hline
\end{tabular}

Unit of observation is the score for a given IAS officer in 2012-13 with at least 8 years of tenure. Suspended is a dummy that is 1 if the IAS officer is suspended in 2012-13. Mean past suspension is the cumulative number of suspensions up to the year before the survey (2011) divided by the total years in service. Respondent FEs are fixed effects for each survey respondent. State $\times$ Intake year FEs are dummies for the state-specific cadre the IAS officer entered with. Standard errors in parentheses, clustered at the individual and the respondent level. ${ }^{* * *} p<0.01$, ${ }^{* *} p<0.05,{ }^{*} p<0.1$ 
Table B4: Subjective performance and home state allocation - linear IV

\begin{tabular}{|c|c|c|c|c|c|c|}
\hline \multirow[b]{3}{*}{ Mean of dep. var } & (1) & $(2)$ & $(3)$ & $(4)$ & $(5)$ & (6) \\
\hline & \multicolumn{6}{|c|}{ Allocated to home state } \\
\hline & 0.359 & 0.365 & 0.353 & 0.359 & 0.362 & 0.360 \\
\hline \multicolumn{7}{|l|}{ Panel A: First-stage } \\
\hline Number of candidates & $\begin{array}{c}-0.021^{* * *} \\
(0.004)\end{array}$ & $\begin{array}{c}-0.020^{* * *} \\
(0.004)\end{array}$ & $\begin{array}{c}-0.021^{* * *} \\
(0.004)\end{array}$ & $\begin{array}{c}-0.021^{* * *} \\
(0.004)\end{array}$ & $\begin{array}{c}-0.021^{* * *} \\
(0.004)\end{array}$ & $\begin{array}{c}-0.020^{* * *} \\
(0.004)\end{array}$ \\
\hline \multicolumn{7}{|l|}{ Panel B: IV } \\
\hline & Pressure & Probity & Effective & Pro-poor & Overall & Index. \\
\hline Mean of dep. var & 3.524 & 3.671 & 3.730 & 3.528 & 3.647 & 3.620 \\
\hline \multirow[t]{2}{*}{ Home state } & $-0.285^{* *}$ & $-0.366^{* *}$ & 0.026 & -0.157 & -0.058 & -0.145 \\
\hline & $(0.134)$ & $(0.155)$ & $(0.117)$ & $(0.132)$ & $(0.132)$ & $(0.119)$ \\
\hline Kleibergen-Paap $F$-statistic & 33.430 & 29.771 & 32.896 & 33.076 & 32.709 & 30.163 \\
\hline Home state $\times$ Caste FEs & $\mathrm{Y}$ & $\mathrm{Y}$ & $\mathrm{Y}$ & $\mathrm{Y}$ & $\mathrm{Y}$ & $\mathrm{Y}$ \\
\hline Intake year FEs & $\mathrm{Y}$ & $\mathrm{Y}$ & Y & $\mathrm{Y}$ & $\mathrm{Y}$ & $\mathrm{Y}$ \\
\hline Respondent FEs & $\mathrm{Y}$ & $\mathrm{Y}$ & $\mathrm{Y}$ & $\mathrm{Y}$ & $\mathrm{Y}$ & $\mathrm{Y}$ \\
\hline State $\times$ Tenure FEs & $\mathrm{Y}$ & $\mathrm{Y}$ & $\mathrm{Y}$ & $\mathrm{Y}$ & $\mathrm{Y}$ & $\mathrm{Y}$ \\
\hline Individual controls & $\mathrm{Y}$ & $\mathrm{Y}$ & $\mathrm{Y}$ & $\mathrm{Y}$ & $\mathrm{Y}$ & $\mathrm{Y}$ \\
\hline Observations & 16,712 & 15,128 & 17,744 & 17,037 & 17,689 & 14,003 \\
\hline
\end{tabular}

Notes: Unit of observation is the score for a given IAS officer in 2012-13 with at least 8 years of tenure. Relating five measures of performance (ability to withstand illegitimate political pressure, probity, effectiveness, pro-poor orientedness and overall rating) to home state allocation. Home state is a dummy that is 1 if the IAS officer is allocated to his or her state of origin. The instrument is the total number of candidates in a given intake year-home state-caste bracket. Caste FEs are dummies for OBC, SC, ST. Rank FEs are fixed effects for each rank in the entry exam. Individual controls are: age at entry, female dummy, a dummy for coming from an urban background, having received an academic distinction, a STEM or Economics degree, a dummy for entering directly after completing education. Standard errors clustered at the caste-home state-intake year level and individual-level. ${ }^{*} p<0.1$, ** $p<0.05$, *** $p<0.01$. 
Table B5: Subjective performance and home state allocation by info source

\begin{tabular}{lccccc}
\hline \hline & $(1)$ & $(2)$ & $(3)$ & $(4)$ & $(5)$ \\
& Pressure & Probity & Effective & Pro-poor & Overall \\
Mean of dep. var & 3.524 & 3.671 & 3.730 & 3.528 & 3.647 \\
\hline Only candidate & $-0.171^{* *}$ & -0.068 & 0.015 & -0.043 & -0.027 \\
& $(0.072)$ & $(0.076)$ & $(0.053)$ & $(0.073)$ & $(0.066)$ \\
$\times$ Network & 0.042 & -0.047 & -0.055 & -0.013 & -0.046 \\
& $(0.082)$ & $(0.087)$ & $(0.065)$ & $(0.090)$ & $(0.072)$ \\
$\times$ Media & 0.039 & 0.002 & -0.025 & 0.009 & -0.002 \\
& $(0.073)$ & $(0.082)$ & $(0.054)$ & $(0.074)$ & $(0.066)$ \\
\hline Home state $\times$ Caste FEs & $\mathrm{Y}$ & $\mathrm{Y}$ & $\mathrm{Y}$ & $\mathrm{Y}$ & $\mathrm{Y}$ \\
Intake year FEs & $\mathrm{Y}$ & $\mathrm{Y}$ & $\mathrm{Y}$ & $\mathrm{Y}$ & $\mathrm{Y}$ \\
Respondent FEs & $\mathrm{Y}$ & $\mathrm{Y}$ & $\mathrm{Y}$ & $\mathrm{Y}$ & $\mathrm{Y}$ \\
State $\times$ Tenure FEs & $\mathrm{Y}$ & $\mathrm{Y}$ & $\mathrm{Y}$ & $\mathrm{Y}$ & $\mathrm{Y}$ \\
Individual controls & $\mathrm{Y}$ & $\mathrm{Y}$ & $\mathrm{Y}$ & $\mathrm{Y}$ & $\mathrm{Y}$ \\
Observations & 16,712 & 15,128 & 17,744 & 17,037 & 17,689 \\
\hline \hline
\end{tabular}

Notes: Unit of observation is the score for a given IAS officer in 2012-13 with at least 8 years of tenure. Relating five measures of performance (ability to withstand illegitimate political pressure, probity, effectiveness, pro-poor orientedness and overall rating) to home state allocation. Home state is a dummy that is 1 if the IAS officer is allocated to his or her state of origin. The instrument only candidate is a dummy that is 1 if the IAS officer was the only candidate in the intake year-home state-caste bracket. Estimates are relative to assessments based on personally knowing the IAS officer. Network (Media) is a dummy that is 1 if the respondent knows the given officer through his/her social network (media). Caste FEs are dummies for OBC, SC, ST. Rank FEs are fixed effects for each rank in the entry exam. Individual controls are: age at entry, female dummy, a dummy for coming from an urban background, having received an academic distinction, a STEM or Economics degree, a dummy for entering directly after completing education. Standard errors clustered at the caste-home state-intake year level and individual-level. * $p<0.1, * * p<0.05, * * * p<0.01$. 
Table B6: Subjective performance and home state allocation by stakeholder

\begin{tabular}{lccccc}
\hline \hline & $(1)$ & $(2)$ & $(3)$ & $(4)$ & $(5)$ \\
& Pressure & Probity & Effective & Pro-poor & Overall \\
Mean of dep. var & 3.524 & 3.671 & 3.730 & 3.528 & 3.647 \\
\hline Only candidate & $-0.207^{* * *}$ & -0.098 & $-0.118^{*}$ & -0.056 & $-0.172^{* * *}$ \\
& $(0.056)$ & $(0.069)$ & $(0.066)$ & $(0.064)$ & $(0.066)$ \\
$\times$ State civil service & 0.069 & 0.034 & 0.098 & -0.099 & 0.135 \\
& $(0.094)$ & $(0.088)$ & $(0.080)$ & $(0.080)$ & $(0.102)$ \\
$\times$ Politicians (MLA) & $0.245^{* * *}$ & -0.033 & $0.163^{*}$ & 0.059 & $0.172^{*}$ \\
& $(0.075)$ & $(0.116)$ & $(0.093)$ & $(0.116)$ & $(0.097)$ \\
$\times$ Large firms & 0.064 & 0.056 & $0.168^{* *}$ & 0.062 & $0.220^{* * *}$ \\
& $(0.070)$ & $(0.078)$ & $(0.078)$ & $(0.074)$ & $(0.070)$ \\
$\times$ Media & 0.029 & 0.037 & $0.159^{* *}$ & 0.046 & $0.167^{*}$ \\
& $(0.094)$ & $(0.091)$ & $(0.074)$ & $(0.097)$ & $(0.089)$ \\
$\times$ NGO & 0.090 & 0.044 & 0.108 & 0.025 & $0.220^{* *}$ \\
& $(0.095)$ & $(0.111)$ & $(0.085)$ & $(0.113)$ & $(0.098)$ \\
\hline Home state $\times$ Caste FEs & $\mathrm{Y}$ & $\mathrm{Y}$ & $\mathrm{Y}$ & $\mathrm{Y}$ & $\mathrm{Y}$ \\
Intake year FEs & $\mathrm{Y}$ & $\mathrm{Y}$ & $\mathrm{Y}$ & $\mathrm{Y}$ & $\mathrm{Y}$ \\
Respondent FEs & $\mathrm{Y}$ & $\mathrm{Y}$ & $\mathrm{Y}$ & $\mathrm{Y}$ & $\mathrm{Y}$ \\
State $\times$ Tenure FEs & $\mathrm{Y}$ & $\mathrm{Y}$ & $\mathrm{Y}$ & $\mathrm{Y}$ & $\mathrm{Y}$ \\
Individual controls & $\mathrm{Y}$ & $\mathrm{Y}$ & $\mathrm{Y}$ & $\mathrm{Y}$ & $\mathrm{Y}$ \\
Observations & 16,712 & 15,128 & 17,744 & 17,037 & 17,689 \\
\hline \hline
\end{tabular}

Notes: Unit of observation is the score for a given IAS officer in 2012-13 with at least 8 years of tenure. Relating five measures of performance (ability to withstand illegitimate political pressure, probity, effectiveness, pro-poor orientedness and overall rating) to home state allocation. Home state is a dummy that is 1 if the IAS officer is allocated to his or her state of origin. The instrument only candidate is a dummy that is 1 if the IAS officer was the only candidate in the intake year-home state-caste bracket. Estimates are relative to assessments provided by IAS officers. Caste FEs are dummies for OBC, SC, ST. Rank FEs are fixed effects for each rank in the entry exam. Individual controls are: age at entry, female dummy, a dummy for coming from an urban background, having received an academic distinction, a STEM or Economics degree, a dummy for entering directly after completing education. Standard errors clustered at the caste-home state-intake year level and individual-level. ${ }^{*} p<0.1,{ }^{* *} p<0.05,{ }^{* * *} p<0.01$. 
Table B7: Standard deviation of performance ratings and home state allocation

\begin{tabular}{lccccc}
\hline \hline Panel A: & $(1)$ & $(2)$ & $(3)$ & $(4)$ & $(5)$ \\
& \multicolumn{5}{c}{ Standard deviation in residual scores } \\
& Pressure & Probity & Effective & Pro-poor & Overall \\
Mean of dep. var & 0.764 & 0.833 & 0.685 & 0.782 & 0.806 \\
\hline Only candidate & -0.037 & -0.014 & -0.048 & -0.050 & 0.010 \\
& $(0.052)$ & $(0.058)$ & $(0.045)$ & $(0.057)$ & $(0.053)$ \\
\hline Home state $\times$ Caste FEs & $\mathrm{Y}$ & $\mathrm{Y}$ & $\mathrm{Y}$ & $\mathrm{Y}$ & $\mathrm{Y}$ \\
Intake year FEs & $\mathrm{Y}$ & $\mathrm{Y}$ & $\mathrm{Y}$ & $\mathrm{Y}$ & $\mathrm{Y}$ \\
State $\times$ Tenure FEs & $\mathrm{Y}$ & $\mathrm{Y}$ & $\mathrm{Y}$ & $\mathrm{Y}$ & $\mathrm{Y}$ \\
Individual controls & $\mathrm{Y}$ & $\mathrm{Y}$ & $\mathrm{Y}$ & $\mathrm{Y}$ & $\mathrm{Y}$ \\
Observations & 1,161 & 1,116 & 1,165 & 1,164 & 1,169 \\
\hline \hline
\end{tabular}

Notes: Unit of observation is the SD for scores given to an IAS officer in 2012-13 with at least 8 years of tenure. Relating the SD of all five measures of performance (ability to withstand illegitimate political pressure, probity, effectiveness, pro-poor orientedness and overall rating) to home state allocation. The standard deviation is calculated based on the performance scores after partialing out respondent fixed effects. Home state is a dummy that is 1 if the IAS officer is allocated to his or her state of origin. The instrument only candidate is a dummy that is 1 if the IAS officer was the only candidate in the intake year-home state-caste bracket. Estimates are relative to assessments based on personally knowing the IAS officer. Network (Media) is a dummy that is 1 if the respondent knows the given officer through his/her social network (media). Caste FEs are dummies for OBC, SC, ST. Rank FEs are fixed effects for each rank in the entry exam. Individual controls are: age at entry, female dummy, a dummy for coming from an urban background, having received an academic distinction, a STEM or Economics degree, a dummy for entering directly after completing education. Standard errors clustered at the caste-home state-intake year level and individual-level. ${ }^{*} p<0.1,{ }^{* *} p<0.05,{ }^{* * *} p<0.01$. 
Table B8: Subjective performance and home state allocation by state-level corruption

\begin{tabular}{lccccc}
\hline \hline & $(1)$ & $(2)$ & $(3)$ & $(4)$ & $(5)$ \\
& Effective & Probity & Pressure & Pro-poor & $\begin{array}{c}\text { Overall } \\
\text { Mean of dep. var }\end{array}$ \\
\hline Only candidate & 3.703 & 3.658 & 3.497 & 3.506 & 3.618 \\
\hline \multirow{2}{*}{ TI corruption index } & -0.054 & $-0.146^{* * *}$ & $-0.157^{* * *}$ & $-0.094^{* *}$ & $-0.094^{*}$ \\
& $(0.039)$ & $(0.047)$ & $(0.041)$ & $(0.042)$ & $(0.048)$ \\
$\times$ HDI & $-0.129^{* *}$ & $-0.134^{* *}$ & $-0.107^{* *}$ & 0.011 & $-0.169^{* * *}$ \\
& $(0.055)$ & $(0.063)$ & $(0.049)$ & $(0.059)$ & $(0.058)$ \\
& 0.006 & -0.021 & -0.020 & 0.084 & -0.031 \\
Home state $\times$ Caste FEs & $(0.048)$ & $(0.057)$ & $(0.047)$ & $(0.056)$ & $(0.052)$ \\
Intake year FEs & $\mathrm{Y}$ & $\mathrm{Y}$ & $\mathrm{Y}$ & $\mathrm{Y}$ & $\mathrm{Y}$ \\
Respondent FEs & $\mathrm{Y}$ & $\mathrm{Y}$ & $\mathrm{Y}$ & $\mathrm{Y}$ & $\mathrm{Y}$ \\
State $\times$ Tenure FEs & $\mathrm{Y}$ & $\mathrm{Y}$ & $\mathrm{Y}$ & $\mathrm{Y}$ & $\mathrm{Y}$ \\
Individual controls & $\mathrm{Y}$ & $\mathrm{Y}$ & $\mathrm{Y}$ & $\mathrm{Y}$ & $\mathrm{Y}$ \\
Observations & 16,676 & 14,083 & 15,644 & 15,969 & 16,621 \\
\hline \hline
\end{tabular}

Notes: Unit of observation is the score for a given IAS officer in 2012-13 with at least 8 years of tenure. Relating five measures of performance (ability to withstand illegitimate political pressure, probity, effectiveness, pro-poor orientedness and overall rating) to home state allocation. Home state is a dummy that is 1 if the IAS officer is allocated to his or her state of origin. The instrument only candidate is a dummy that is 1 if the IAS officer was the only candidate in the intake year-home state-caste bracket. Estimates are relative to assessments provided by IAS officers. Caste FEs are dummies for OBC, SC, ST. Rank FEs are fixed effects for each rank in the entry exam. Individual controls are: age at entry, female dummy, a dummy for coming from an urban background, having received an academic distinction, a STEM or Economics degree, a dummy for entering directly after completing education. Standard errors clustered at the caste-home state-intake year level and individual-level. ${ }^{*} p<0.1,{ }^{* *} p<0.05,{ }^{* * *} p<0.01$. 
Table B9: Career performance and home state allocation

\begin{tabular}{lcccc}
\hline \hline By tenure & $(1)$ & $(2)$ & $(3)$ & $(4)$ \\
& Pressure & Suspended & In Delhi & Payscale \\
Mean of dep. var & 3.524 & 0.771 & 0.178 & 3.275 \\
\hline Only candidate $\times 1-3$ years & - & 0.141 & $0.061^{* * *}$ & -0.028 \\
& & $(0.188)$ & $(0.011)$ & $(0.018)$ \\
$\times 4-8$ years & 0.012 & $-0.178^{* *}$ & -0.012 & 0.007 \\
& $(0.161)$ & $(0.080)$ & $(0.007)$ & $(0.022)$ \\
$\times 9-12$ years & -0.108 & $-0.394^{*}$ & $-0.069^{* * *}$ & 0.021 \\
& $(0.093)$ & $(0.230)$ & $(0.021)$ & $(0.025)$ \\
$\times 13-15$ years & $-0.202^{* *}$ & 0.686 & $-0.132^{* * *}$ & $0.129^{* * *}$ \\
& $(0.097)$ & $(1.074)$ & $(0.031)$ & $(0.040)$ \\
$\times 16-24$ years & $-0.107^{* *}$ & -0.684 & $-0.074^{* *}$ & $0.079^{* *}$ \\
& $(0.050)$ & $(0.473)$ & $(0.032)$ & $(0.032)$ \\
$\times 25-29$ years & 0.042 & 0.258 & $-0.152^{* * *}$ & 0.055 \\
& $(0.082)$ & $(1.201)$ & $(0.052)$ & $(0.074)$ \\
$\times \geq 30$ years & $-0.409^{* * *}$ & 7.537 & $-0.435^{* * *}$ & $0.167^{*}$ \\
& $(0.132)$ & $(7.154)$ & $(0.090)$ & $(0.090)$ \\
\hline Year FEs & - & $\mathrm{Y}$ & $\mathrm{Y}$ & $\mathrm{Y}$ \\
State $\times$ Tenure FEs & $\mathrm{Y}$ & $\mathrm{Y}$ & $\mathrm{Y}$ & $\mathrm{Y}$ \\
Home state $\times$ Caste FEs & $\mathrm{Y}$ & $\mathrm{Y}$ & $\mathrm{Y}$ & $\mathrm{Y}$ \\
Intake year FEs & $\mathrm{Y}$ & $\mathrm{Y}$ & $\mathrm{Y}$ & $\mathrm{Y}$ \\
Rank FEs & $\mathrm{Y}$ & $\mathrm{Y}$ & $\mathrm{Y}$ & $\mathrm{Y}$ \\
Individual controls & $\mathrm{Y}$ & $\mathrm{Y}$ & $\mathrm{Y}$ & $\mathrm{Y}$ \\
Sample & Cross-section & & IAS-Year panel \\
Observations & 16,712 & 42,682 & 42,682 & 42,681 \\
\hline \hline
\end{tabular}

Notes: Unit of observation is the IAS posting. Relating career outcomes to home state allocation, broken down by tenure. In Column 1, the dependent variable is the cross-sectional performance score for the ability to withstand illegitimate political pressure. In Column 2, suspended is a dummy that is 1 if the IAS officer is suspended (scaled $\times 100$ ). In Column 3, In Delhi is a dummy that is 1 if the officer is serving in the Central Government. In Column 5, Payscale denotes the payscale of the IAS officer (1 lowest, 7 highest) in a given year. The instrument only candidate is a dummy that is 1 if the IAS officer was the only candidate in the intake year-home state-caste bracket. State $\times$ Tenure FEs are state-specific fixed effects for each year of experience in the IAS. Standard errors clustered at the caste-home state-intake year and individual IAS officer level. ${ }^{*} p<0.1,{ }^{* *} p<0.05,{ }^{* * *} p<0.01$. 
Table B10: Transfers and promotions around Chief Minister turnover

\begin{tabular}{|c|c|c|}
\hline Mean of dep. var & $\begin{array}{c}(1) \\
\text { Transfer } \\
0.126\end{array}$ & $\begin{array}{c}(2) \\
\text { Promoted } \\
0.0231\end{array}$ \\
\hline Month around transition $t=-6$ & $\begin{array}{c}0.012^{* * *} \\
(0.003)\end{array}$ & $\begin{array}{c}0.004^{* *} \\
(0.001)\end{array}$ \\
\hline Month around transition $t=-5$ & $\begin{array}{c}0.017^{* * *} \\
(0.003)\end{array}$ & $\begin{array}{c}0.008^{* * *} \\
(0.002)\end{array}$ \\
\hline Month around transition $t=-4$ & $\begin{array}{c}0.014^{* * *} \\
(0.003)\end{array}$ & $\begin{array}{c}0.009 * * * \\
(0.002)\end{array}$ \\
\hline Month around transition $t=-3$ & $\begin{array}{c}0.019^{* * *} \\
(0.003)\end{array}$ & $\begin{array}{c}0.005^{* * *} \\
(0.001)\end{array}$ \\
\hline Month around transition $t=-2$ & $\begin{array}{c}0.012^{* * *} \\
(0.003)\end{array}$ & $\begin{array}{c}0.007^{* * *} \\
(0.001)\end{array}$ \\
\hline Month around transition $t=0$ & $\begin{array}{c}0.038^{* * *} \\
(0.003)\end{array}$ & $\begin{array}{c}0.009 * * * \\
(0.001)\end{array}$ \\
\hline Month around transition $t=1$ & $\begin{array}{c}0.063^{* * *} \\
(0.003)\end{array}$ & $\begin{array}{c}0.016^{* * *} \\
(0.002)\end{array}$ \\
\hline Month around transition $t=2$ & $\begin{array}{c}0.028^{* * *} \\
(0.003)\end{array}$ & $\begin{array}{c}0.010^{* * *} \\
(0.002)\end{array}$ \\
\hline Month around transition $t=3$ & $\begin{array}{c}0.028^{* * *} \\
(0.003)\end{array}$ & $\begin{array}{c}0.008^{* * *} \\
(0.002)\end{array}$ \\
\hline Month around transition $t=4$ & $\begin{array}{c}0.027^{* * *} \\
(0.003)\end{array}$ & $\begin{array}{c}0.010^{* * *} \\
(0.002)\end{array}$ \\
\hline Month around transition $t=5$ & $\begin{array}{c}0.024^{* * *} \\
(0.003)\end{array}$ & $\begin{array}{c}0.009 * * * \\
(0.002)\end{array}$ \\
\hline Month around transition $t=6$ & $\begin{array}{c}0.026^{* * *} \\
(0.003)\end{array}$ & $\begin{array}{c}0.006^{* * *} \\
(0.002)\end{array}$ \\
\hline IAS officer $\times$ Turnover event FEs & $\mathrm{Y}$ & $\mathrm{Y}$ \\
\hline Observations & 148,330 & 148,330 \\
\hline
\end{tabular}

Notes: Unit of observation is the IAS officer-month. Balanced sample of IAS officer-Chief Minister transitions around six months windows of Chief Minister appointments. Relating transfers and promotions to Chief Minister appointments. Transfer is a dummy that is 1 if the IAS officer was transferred in a given month. Promoted is a dummy that is 1 if the officer was promoted to a higher payscale. Months around transition are dummies for each month in the six month window around which the new Chief Minister is appointed, with $t=0$ denoting the month of appointment. The omitted category is the month before the Chief Minister appointment $(t=-1)$. IAS officer $\times$ Turnover event FEs are Chief minister turnover-specific individual officer fixed effects. Standard errors clustered at the individual IAS officer level. $* p<0.1, * * p<0.05, * * * p<0.01$. 
Table B11: Transfer probability by seniority and home state allocation

\begin{tabular}{|c|c|}
\hline Mean of dep. var & $\begin{array}{c}(1) \\
\text { Transfer } \\
0.126\end{array}$ \\
\hline Years in IAS: $1-3 \times$ Chief Minister appointed $[t, t-1]$ & $\begin{array}{l}-0.008 \\
(0.006)\end{array}$ \\
\hline Years in IAS: $4-8 \times$ Chief Minister appointed $[t, t-1]$ & $\begin{array}{c}0.022^{* * *} \\
(0.004)\end{array}$ \\
\hline Years in IAS: $9-12 \times$ Chief Minister appointed $[t, t-1]$ & $\begin{array}{c}0.044^{* * *} \\
(0.005)\end{array}$ \\
\hline Years in IAS: $13-15 \times$ Chief Minister appointed $[t, t-1]$ & $\begin{array}{c}0.032^{* * *} \\
(0.007)\end{array}$ \\
\hline Years in IAS: $16-24 \times$ Chief Minister appointed $[t, t-1]$ & $\begin{array}{c}0.043^{* * *} \\
(0.004)\end{array}$ \\
\hline Years in IAS: $\geq 25 \times$ Chief Minister appointed $[t, t-1]$ & $\begin{array}{c}0.034^{* * *} \\
(0.008)\end{array}$ \\
\hline Years in IAS: $1-3 \times$ Chief Minister appointed $[t, t-1] \times$ Only candidate & $\begin{array}{l}-0.006 \\
(0.018)\end{array}$ \\
\hline Years in IAS: $4-8 \times$ Chief Minister appointed $[t, t-1] \times$ Only candidate & $\begin{array}{l}-0.022 \\
(0.014)\end{array}$ \\
\hline Years in IAS: $9-12 \times$ Chief Minister appointed $[t, t-1] \times$ Only candidate & $\begin{array}{l}-0.031 \\
(0.019)\end{array}$ \\
\hline Years in IAS: $13-15 \times$ Chief Minister appointed $[t, t-1] \times$ Only candidate & $\begin{array}{l}-0.015 \\
(0.027)\end{array}$ \\
\hline Years in IAS: $16-24 \times$ Chief Minister appointed $[t, t-1] \times$ Only candidate & $\begin{array}{c}0.041^{*} \\
(0.025)\end{array}$ \\
\hline Years in IAS: $\geq 25 \times$ Chief Minister appointed $[t, t-1] \times$ Only candidate & $\begin{array}{l}0.102^{*} \\
(0.058)\end{array}$ \\
\hline Controls & $\mathrm{Y}$ \\
\hline Years in IAS bin FEs & $\mathrm{Y}$ \\
\hline IAS officer $\times$ Turnover event FEs & $\mathrm{Y}$ \\
\hline Observations & 148,330 \\
\hline
\end{tabular}

Notes: Unit of observation is the IAS officer-month. Balanced sample of IAS officer-Chief Minister transitions around six months windows of Chief Minister appointments. Relating transfers to Chief Minister appointments. Transfer is a dummy that is 1 if the IAS officer was transferred in a given month. Only candidate is a dummy that is 1 if the IAS officer was the only candidate in the intake yearhome state-caste bracket. The controls are : Home state $\times$ Caste FEs (Caste FEs are dummies for OBC, SC, ST); year of intake FEs; only candidate, entry exam score, entry exam rank fixed effects for each rank in the entry exam, age at entry, female dummy, a dummy for coming from an urban background, having received an academic distinction, a STEM or Economics degree, dummies for previous job type. Years in IAS FEs are fixed effects for bins of years served in the IAS, with bins corresponding to those reported in the table $(1-3,4-8,9-12,13-15,16-24, \geq 25)$. Standard errors clustered at the individual IAS officer level. ${ }^{*} p<0.1,{ }^{* *} p<0.05,{ }^{* * *} p<0.01$. 
Table B12: Robustness: Home district connectedness with different cut-offs

\begin{tabular}{|c|c|c|c|c|c|}
\hline \multirow[b]{3}{*}{ Mean of dep. var } & (1) & $(2)$ & $(3)$ & $(4)$ & $(5)$ \\
\hline & \multicolumn{5}{|c|}{ IAS officer is promoted } \\
\hline & 0.0235 & 0.0235 & 0.0235 & 0.0235 & 0.0236 \\
\hline Chief Minister appointed $[t, t-1]$ & $\begin{array}{c}0.007^{* * *} \\
(0.002)\end{array}$ & $\begin{array}{c}0.007^{* * *} \\
(0.002)\end{array}$ & $\begin{array}{c}0.006^{* * *} \\
(0.002)\end{array}$ & $\begin{array}{c}0.003 \\
(0.025)\end{array}$ & $\begin{array}{c}0.003 \\
(0.002)\end{array}$ \\
\hline$\times$ Home connected: Switch in & $\begin{array}{c}0.025^{* *} \\
(0.012)\end{array}$ & $\begin{array}{c}0.026^{* *} \\
(0.012)\end{array}$ & $\begin{array}{c}0.024^{* *} \\
(0.010)\end{array}$ & $\begin{array}{c}0.026^{* * *} \\
(0.008)\end{array}$ & $\begin{array}{c}0.025^{* * *} \\
(0.007)\end{array}$ \\
\hline$\times$ Home connected: Switch out & $\begin{array}{c}0.001 \\
(0.014)\end{array}$ & $\begin{array}{l}-0.000 \\
(0.010)\end{array}$ & $\begin{array}{c}0.001 \\
(0.008)\end{array}$ & $\begin{array}{c}0.008 \\
(0.006)\end{array}$ & $\begin{array}{l}0.004 \\
(0.006)\end{array}$ \\
\hline Year $\times$ Month FEs & $\mathrm{Y}$ & $\mathrm{Y}$ & $\mathrm{Y}$ & $\mathrm{Y}$ & $\mathrm{Y}$ \\
\hline IAS officer $\times$ Turnover event FEs & $\mathrm{Y}$ & Y & $\mathrm{Y}$ & $\mathrm{Y}$ & $\mathrm{Y}$ \\
\hline Sample & \multicolumn{5}{|c|}{ Home state officers } \\
\hline Cut-off for home connectedness & 15 miles & 25 miles & 50 miles & 75 miles & 100 miles \\
\hline Number of switching in & 167 & 206 & 357 & 566 & 727 \\
\hline Number of switching out & 169 & 202 & 377 & 499 & 665 \\
\hline Observations & 46,947 & 46,947 & 46,947 & 46,947 & 46,947 \\
\hline
\end{tabular}

Notes: Unit of observation is the IAS officer-month. Balanced sample of IAS officer-Chief Minister transitions around six months windows of Chief Minister appointments. Relating transfers, promotions, demotions and lateral moves to social connections with the incoming Chief Minister. Chief Minister appointed is a dummy that is 1 in the month the Chief Minister is appointed as well as the month after $([t, t+1])$. An IAS officer and Chief Minister are defined as home connected if their home districts are less than 15, 25, 50, 75 and 100 miles apart (Columns 1-5). Home connected: Switch in is a dummy that is 1 if the officer moved from not being home connected to home connected. Home connected: Switch out is a dummy that is 1 if the officer moved from home connected to not being home connected. The sample is restricted to home state officers only. Standard errors clustered at the individual IAS officer level. * $p<0.1, * * p<0.05, * * * p<0.01$. 


\section{B Appendix Documentation}

\section{B.1 Data description: Performance survey}

We collected cross-sectional data on the subjective assessments of IAS officers in the 14 main states of India ${ }^{22}$ for 2012-13. IAS officers were assessed on five dimensions: (i) effectiveness on the job, (ii) probity ${ }^{23}$ (iii) ability to withstand illegitimate political pressure, (iv) propoor orientation, and (v) overall rating. ${ }^{24}$ All dimensions are scored on a 5 point integer scale, where 1 is the lowest and 5 the highest performance.

To obtain assessments from a wide range of stakeholders, we elicited these subjective assessments from respondents of six societal groups in each state: (i) a random sample of IAS officers, (ii) a random sample of state civil servants, (iii) politicians, drawn from a random sample of members of the legislative assembly (MLA), (iv) industry, business and professional associations, comprised of the highest representatives for the major associations, ${ }^{25}(\mathrm{v})$ print and TV media, comprised of key journalists covering politics for the largest newspapers and TV stations by circulation and viewership respectively, and finally (vi) civil society, comprised of the highest representatives of major NGOs, trade unions ${ }^{26}$ and think-tanks. For each state, we sampled about 10 respondents from each of the groups. ${ }^{27}$

We compiled a list of all centrally recruited IAS officers for each state. In each state, interviewers then systematically worked through the list, asking respondents to provide assessments for each known candidate. We excluded junior officers with less than 8 years' tenure as they are often in district postings and less visible. Finally, we recorded the source of information to account for reporting biases, differentiating between information obtained through personal exposure, friends or social networks, or the media.

Table 1 provides summary statistics of the 360 degrees $^{28}$ measures. The sample sizes range from $N=15,153$ for the probity measure to $N=17,753$ for the effectiveness measure. The number of complete assessments across all dimensions is $N=14,037$. We were able to elicit scores for about $70 \%$ of all IAS officers in our sample. All dimensions are correlated, with the highest correlation being between pro-poor orientation and the ability to withstand illegitimate political pressure.

\footnotetext{
${ }^{22}$ These states are: Andhra Pradesh, Bihar, Gujarat, Haryana, Karnataka, Kerala, Madhya Pradesh, Maharashtra, Orissa, Punjab, Rajasthan, Tamil Nadu, Uttar Pradesh and West Bengal. We excluded joint cadres (Union Territories, Assam - Meghalaya, Manipur - Tripura), as well as the smaller states (Jammu \& Kashmir, Nagaland) and the new cadres resulting from state splits in 2000 (Jharkhand, Uttarakhand, Chhattisgarh) from the sample.

${ }^{23}$ Note that a higher value on the scale corresponds to less corruption.

${ }^{24}$ The exact questions are: (i) "How would you rate his/her effectiveness in his/her assignment?" (ii) "How much do you feel this officer uses his/her official position for making money?" (iii) "How much do you feel this officer can withstand illegitimate political pressure?" (iv) "How sensitive is this officer to the needs of the poor and weaker sections in society?" (v) "What is your overall rating of this officer?".

${ }^{25}$ Confederation of Indian Industry (CII), the Federation of Indian Chambers of Commerce and Industry (FICCI), the Associated Chambers of Commerce and Industry of India (ACCI).

${ }^{26}$ All India Trade Union, Secretariat Employees Union.

${ }^{27}$ For logistical reasons, we were unable to survey state civil servants in Gujarat and IAS officers in Punjab.

${ }^{28}$ The term "360 degree" feedback refers to multi-source feedback used by organizations to elicit information about employees' work-related performance.
} 


\section{B.2 Converting unmatched insider allocations}

In presence of open unreserved insider vacancies, the unreserved insider vacancy can be allocated to insider IAS officers from SC/ST and OBC (following the exact order) if there is an SC/ST (or OBC) outsider vacancy to allow for the exchange: For example, if Gujarat has received two unreserved insider vacancies but only one Gujarati general caste to fill the first slot, the second slot is opened to Gujarati SC/ST insiders, and if those are not available, to OBC insiders. The reallocation, however, is only permitted when there is a corresponding outsider vacancy that can be converted to an unreserved outsider vacancy to maintain the quota among the caste vacancies. A Gujarati insider SC/ST then can only fill the unreserved insider vacancy if a SC/ST outsider vacancy is available for exchange. Similar rules apply for unfilled SC/ST or OBC insider vacancies. Open SC/ST insider vacancies that could not be filled are first relaxed to allow for $\mathrm{OBC}$ insider candidates and then to general candidates. Open OBC vacancies, similarly, can first be filled by SC/ST insider candidates and then by general candidates (in both cases provided there is a corresponding outsider slot for exchange). Any remaining open insider vacancies that could not be filled despite the relaxation of the quotas are converted to outsider vacancies to ensure all vacancies are filled.

\section{B.3 Outsider allocation}

The allocation of the outsiders and those who failed to be allocated to their preferred home state (and are consequently converted to outsiders) is done according to a rotating roster system. The roster is created by arranging all 24 cadres in alphabetical order and dividing them into four groups. These groups are devised on the basis of an average intake by each group, which over a period of time is roughly equal:

1. Group I: Andhra Pradesh, Assam-Meghalaya, Bihar, Chhattisgarh and Gujarat

2. Group II: Haryana, Himachal Pradesh, Jammu \& Kashmir, Jharkhand, Karnataka, Kerala and Madhya Pradesh

3. Group III: Maharashtra, Manipur-Tripura, Nagaland, Orissa, Punjab, Rajasthan and Sikkim

4. Group IV: Tamil Nadu, AGMUT (UT Cadre), Uttaranchal, Uttar Pradesh and West Bengal

The outsider candidates are allocated in the order of merit across the four groups for the outsider available vacancies (including those that have been converted from insider vacancies). In the first cycle, all candidates are allocated to their matching caste vacancy in the four states of Group I, starting with Andhra Pradesh. In the second cycle, the remaining candidates are allocated to their matching caste vacancies in Group II and so on. Since states who receive officers earlier in the allocation process will receive higher ranked recruits, the order of the groups shuffles each year to ensure that all states receive officers 
of comparable quality. In Appendix Figure A4, for example, Group III is the first group in 2006, followed by Group IV, Group I and Group II. In the subsequent year, the groups will rotate and the allocation of outsiders will commence with Group II first, followed by Group III, Group IV and Group I. 